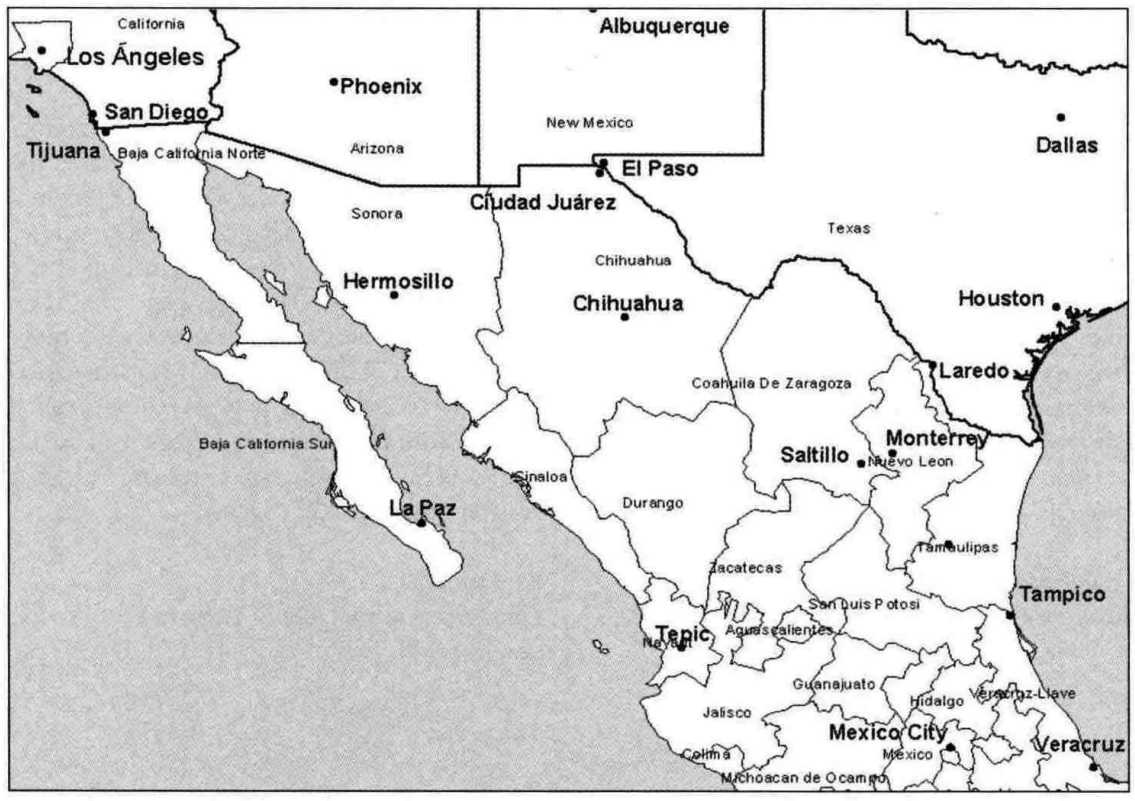




\section{Ma. Eugenia Cbaoul Pereyra}

Investigadora de tiempo completo del Instituto de Investigaciones Dr. José María Luis Mora en el Área de Historia Social y Cultural. Imparte la materia de Historia Sociopolítica de México en el Instituto Tecnológico Autónomo de México. Entre sus publicaciones recientes destacan: "La instrucción municipal, un espejo de la ciudad. La gestión educativa del Ayuntamiento de México (1867-1896)" y "El Ayuntamiento de la ciudad de México y los maestros municipales, 1867-1896". Actualmente trabaja en su tesis doctoral sobre la historia de la escuela pública urbana en la ciudad de México durante los últimos años del porfiriato y de la revolución.

\section{Resumen}

Este artículo busca comprender la escuela elemental porfiriana en la ciudad de México como un complejo espacio de actuación social. A través de un análisis que integra la variable espacial ofrece un planteamiento diferente a los estudios curriculares y políticos realizados hasta ahora. La reconstrucción de la forma que adquirió la escuela como lugar permite al lector "mirar" el movimiento cotidiano de la vida escolar y, de esa manera, buscar una explicación a los problemas tales como la integración social hacia el sistema educativo en la ciudad, la inasistencia escolar, el control disciplinario y la deserción a principios del siglo $\mathrm{xx}$.

Palabras clave:

Escuela elemental, porfiriato, espacio, vida cotidiana, ciudad.

\section{Abstract}

This article seeks to understand the way Porfirian elementary schools in Mexico City operated as complex spheres of social interaction. Through an analysis that incorporates the spatial variable, it provides a different perspective from the curricular and political studies undertaken to date. The reconstruction of the form acquired by schools as a specific place enables the reader to "see" the everyday movement of school life and thereby find an explanation to problems such as social integration into the educational system in the city, absence from school, disciplinary control and drop out rates in the early $20^{\text {th }}$ century.

Key words:

Elementary school, era of Porfirio Díaz, space, everyday life, city.

Fecha de recepción: febrero de 2004

Fecha de aceptación: junio de 2004 


\title{
La escuela nacional elemental en la ciudad de México como lugar, 1896-1910
}

\author{
Ma. Eugenia Chaoul Pereyra
}

$\mathrm{Q}$

uizá la pregunta pertinente sería: ¿se puede entender, desde la distancia que da el tiempo, a la escuela elemental porfiriana como un complejo espacio de actuación social en el que se represente el movimiento diario de la vida escolar? De pronto, uno mismo se percibe como espectador en medio de la fluidez cotidiana, del ir y venir en el aula para observar, a través de la mirada de los maestros plasmada en los informes y registros, cómo estos mismos maestros, las autoridades y los alumnos mismos buscaron construir la escuela como un lugar.

El espacio se transforma en lugar cuando adquiere un significado y un sentido. Lleva dentro de sí un tiempo: el de la intimidad, el de las relaciones diarias de lo vivido y el de la rutina de los que ahí se encuentran. Por lo tanto, el lugar no es sólo una referencia objetiva o externa, sino también una construcción de la experiencia y de la interacción. El espacio histórico se percibe como lugar al dejar impresos los símbolos y las huellas de las relaciones de un pasado. En ese sentido, la ordenación y la configuración del espacio escolar están referidas a un proceso de vida. ${ }^{1}$

\footnotetext{
${ }^{1}$ Sobre espacio y lugar existe una amplia discusión que involucra varios campos académicos. Por una parte los geógrafos atienden a una diferencia básica:
}

El propósito de este trabajo es presentar el avance de una investigación más amplia que busca analizar la compleja red de relaciones sociales que se gestó en el interior de la escuela pública urbana como lugar, y trata de dar cuenta de la heterogeneidad y complejidad del sistema escolar elemental en la ciudad de México hacia finales del porfiriato. Pretendo mostrar cómo el espacio escolar no fue un simple contenedor $\mathrm{o}$ un soporte material de las activi-

el espacio es el que permite el movimiento y la actividad, en tanto que el lugar es la pausa, un centro de valores establecidos. Véanse, por ejemplo, los trabajos de Tuan, Space, 1989; Rapoport, Human, 1977. In cambio, para los antropólogos y los sociólogos, el espacio se entiende como contenedor de las actividides sociales, como un escenario de interacción o un foro en sentido teatral. Véase, por ejemplo, Amerlinck y Bontempo, Entorno, 1994. En teoría social, Giddens prefiere utilizar el concepto de sede para denotar el uso del espacio como escenario de interacción. Para este autor la sede más que el lugar tiene propiedades de escenarios en donde los agentes construyen encuentros sistemáticos por un espacio y un tiempo. Véase Giddens, Constitución, 1988. Por último, pari la narrativa histórica, Certeau propone que el lugar es el orden según el cual los elementos se distribuyen en relaciones de coexistencia en un sitio propio. En tanto que espacio es un cruzamiento de movilidades. Véase Certeau, Invención, 1999. La propuesta que sustenta esta nota se basa en tratar de historiar dichos conceptos. 
dades escolares, sino un actor más al imponer sus propias características en la interacción entre alumnos, maestros y autoridades. Propongo que el espacio fue un elemento activo que influyó en la estructuración misma de la organización escolar. ${ }^{2}$

En los últimos años, las investigaciones sobre la educación en el porfiriato han enfocado sus estudios hacia la importancia que ésta ha desempeñado en el desarrollo del Estado, y han fijado su preocupación en destacar los aspectos ideológicos y legales, los conflictos y las luchas por el poder, así como los procesos de decisión política. La historiografia ha hecho énfasis en las causas y los grandes procesos nacionales, pero ha dado por sentado, en general, que los cambios asociados al proceso de centralización educativa y al ejercicio del Estado docente -durante los últimos años del gobierno de Díaz-conllevaron a una modernización del sistema escolar. ${ }^{3}$ Esta causalidad no siempre es clara cuando no sabemos cómo las ideas asociadas a la nue-

\footnotetext{
${ }^{2}$ Este trabajo forma parte de la tesis doctoral.

${ }^{3}$ Entre las obras más representativas que comparten este enfoque son: Díaz, "Escuela",1979; Martínez, Origen, 1981; Vaughan, Estado, 1982; Bazant, Historia, 1995; Arnaut, Federalizacion, 1998; Loyo, Gobiernos, 1999. En cuanto a la trayectoria del Estado docente, se puede decir que, si bien la tarea educativa había recibido atención preferente desde los gobiernos de la república restaurada, no es sino hasta el porfiriato que el ejecutivo federal logró ampliar sus funciones. Aunque nunca pudo extender su jurisdicción más allá del Distrito Federal y territorios, algunas acciones como la creación de la Normal de Maestros, la federalización de escuelas municipales y la puesta en marcha de la Subsecretaría de Instrucción Pública, le permitieron intervenir en el manejo de la instrucción. En 1905 se creó la Secretaría de Instrucción Pública y Bellas Artes al mando de Justo Sierra, quien logró en 1908 que el ejecutivo tuviera capacidad de legislar en materia educativa en el ámbito federal.
}

va racionalidad adquirían sentido en la práctica diaria; o bien, si los elementos discursivos sobre higiene, uniformidad y las nuevas formas de enseñanza tenían cabida en la dinámica escolar.

Se sabe que para la última década del siglo XIX, la gran cruzada de la política educativa se centró en impulsar la educación elemental como medio para lograr la integración nacional. Si bien la autoridad del Ministerio de Justicia e Instrucción Pública estaba restringida al Distrito Federal y territorios, todo un plan de acción se había puesto en marcha para abrir los márgenes de su actuación y lograr un mayor control en los programas de la educación básica en la república. Uno de los mecanismos empleados por el ejecutivo fue tratar de buscar consensos mediante el Congreso de Instrucción realizado entre 1889 y 1890 , para unificar criterios en materia educativa entre los estados de la federación. Esto le permitiría conseguir la tan anhelada reglamentación de la obligatoriedad de la enseñanza elemental en 1891 y, con ello, obtener una especie de pacto federal sobre la forma que debía tener la educación en el país.

Esta normatividad marcaría, por un lado, la culminación de un largo proceso iniciado desde 1867 con la Ley Juarista de Instrucción Pública y, por otro, aseguraría también el punto de partida del proceso educativo del porfiriato, por medio del cual el Estado trató de extender su ámbito de acción en la educación básica y el inicio de una progresiva apropiación de funciones docentes.

Lo cierto es que la obligatoriedad se había insertado en un proceso de planeación más amplio iniciado cuatro años antes con la creación de la Escuela Normal en 1887 , que había previsto la capacita- 
ción de un cuerpo especializado en la docencia, posibilitando con ello difundir los mismos contenidos educativos. Posteriormente, el relevo de los ayuntamientos en el Distrito Federal y territorios en la impartición de instrucción pública en 1896, le permitirían al ejecutivo buscar la uniformidad de la educación primaria y legitimar la actuación de un Estado educador.

A partir de entonces, la escuela elemental en el ámbito federal se llamaría Nacional, y los planteles de la capital se convertirían en los escaparates que darían cuenta de los cambios propuestos para que, si era voluntad soberana de los gobiernos estatales, los siguieran y adoptaran. A pesar de que, con todas estas medidas, el gobierno no pudo extender su actuación mas allá del ámbito urbano, la idea era que la escuela en la ciudad fuera el modelo que exhibiera una nueva racionalidad organizativa que desplegara estrategias homologadoras en cuanto a programas de estudio y condiciones educativas, para lograr un efecto de demostración frente a la diversidad que hasta entonces presentaba la enseñanza en las distintas entidades federativas. Se intentaba, además, que su visibilidad se insertara también en un espacio, que para principios del siglo $\mathrm{xx}$ buscaba atraer la atención como centro impulsor de la modernidad a través de sus múltiples realizaciones, como el alumbrado público, los nuevos fraccionamientos, las grandes avenidas o el drenaje profundo. ${ }^{4}$

\footnotetext{
${ }^{4}$ El lugar se crea por su visibilidad y la ciudad es un lugar, un centro de significados por excelencia en el cual se hacen altamente visibles los símbolos. La ciudad es en sí misma un símbolo. La ciudad atrae la atención hacia sí misma. Véase Tuan, Space, 1989.
}

El interés por promover la educación elemental suscitó la participación no sólo de pedagogos, sino de higienistas, quienes volcaron la mirada hacia los edificios escolares y buscaron dilucidar cómo se podían mejorar las condiciones de enseñaza en los planteles de la ciudad. La escuela, tal como era entendida desde el punto de vista médico, era un "sitio obligado donde concurrían todas las unidades sociales". Y su función no sólo debía remitirse a la enseñanza de los conocimientos necesarios para la vida, sino formar una niñez sana y robusta. Por lo tanto, cuidar el elemento escolar era "el mejor modo de preparar la virilidad social".

Para los pedagogos, la escuela moderna debía promover el desenvolvimiento armónico de las facultades físicas, intelectuales, estéticas y morales del niño que ahora era considerado el centro del universo pedagógico. Se buscaba suprimir las prácticas de la enseñanza memorista, enciclopédica y autoritaria en las que se basaba la instrucción, para dar paso a una educación práctica que formara hábitos en los alumnos y los preparara para la sociedad. El método simultáneo con un maestro frente al grupo debería sustituir al mutuo, que recurría a la ayuda de alumnos avanzados para enseñar a sus compañeros. Además, se prohibieron los castigos corporales. Siguiendo esos lineamientos, el medio físico de los planteles debería tener las condiciones que garantizaran un mejor aprovechamiento y un ambiente

\footnotetext{
${ }^{5}$ El interés por los edificios escolares partió principalmente de los médicos higienistas en el Congreso Higiénico-Pedagógico celebrado en 1882, véase Memorias, 1883; planteamientos similares los volvemos a encontrar en Ruiz, Tratado, 1900 y en publicaciones como "Cartilla", 1903.
} 
que favoreciera el desarrollo integral del educando. ${ }^{6}$

Con esas ideas se habían estudiado las condiciones que debía llenar una casa destinada al establecimiento de educación primaria. Además, se habían especificado cuáles eran los tipos de mobiliario que debían preferirse dependiendo de las tallas de los niños, de las condiciones de los útiles y los libros para que no presentaran un peligro para la salud, de la distribución de los trabajos escolares para que no causaran una saturación mental en los alumnos y de las precauciones para evitar el contagio en las escuelas.

Uno de los aspectos en los que se había insistido era en la importancia de construir edificios escolares ad boc que incorporaran los requerimientos espaciales para cumplir con el programa de estudios. $^{7}$ Se había especificado que, de no poder ser esto posible, entonces las escuelas públicas no deberían situarse en casas de vecindad y los planteles contarían con salones de clases suficientes para atender a los diferentes grados escolares. Se insistió en separar a los niños pequeños de los grandes, así como crear grupos de no más de 50 alumnos para que su estancia fuera cómoda. ${ }^{8}$ Era claro que al plantear estas

${ }^{6}$ Véase Loyo, Gobiernos, 1999, pp. 7-8.

${ }^{7}$ En 1906 se instauró la Junta Directiva de Edificios de Instrucción Primaria del Distrito Federal que construyó cinco edificios escolares para escuelas elementales en la ciudad. Sin embargo, menos de cuatro años después, no habiendo correspondido plenamente a los propósitos para los que fue creada dicha Junta, se derogó el decreto de su creación. Véase Boletín de Instrucción Pública, junio-diciembre de 1906, t. VI, p. 883.

${ }^{8}$ Véase Meneses, Tendencias, 1986, pp. 307 y 480-494. especificaciones no se desconocían las discusiones que a escala mundial se llevaban a cabo en torno a las condiciones que debían cubrir los establecimientos escolares.

Países como Francia, Suiza e Inglaterra habían expedido reglamentos hacia finales del siglo XIX que disponían cuáles debían ser las condiciones higiénicas escolares: la superficie en metros cuadrados por alumno, la cubicación de aire por niño, las condiciones acústicas y visuales necesarias, e incluso los requerimientos en torno a la ubicación de los planteles. Una marcada obsesión por definir la escuela como un espacio diferenciado -como un ambiente especializado- hacía que las especificaciones fueran extremadamente puntuales en torno a los rasgos que debían cubrir los edificios escolares. El inmueble donde se ubicara la escuela tendría que ser entendido como un espacio para la realización de actividades determinadas, tal como era explicado en un tratado español de higiene escolar en 1886:

No sólo por la aglomeración de individuos, sino asimismo por la vida que éstos están llamados a hacer, difiere la escuela notablemente de la habitación ordinaria. Dentro de la escuela se impone a la actividad de los niños direcciones que raras veces se encuentra sometida en el hogar doméstico.'

La escuela no debía temitirse sólo al salón de clases, sino a lugares más amplios donde los niños pudieran satisfacer las necesidades de actividad física, aseo y recreación. Un espacio y un tiempo definidos debían presentar un contraste con las actividades en otros ámbitos de la vida social.

${ }^{9}$ Alcántara, Tratado, 1886, p. 97. 
A finales de la década de 1900 en la ciudad de México, existían 126 escuelas nacionales elementales para 37171 niños. ${ }^{10}$ De ellas, sólo once eran edificios propiedad federal y únicamente cinco contaban con características específicamente escolares. Por lo tanto, la mayoría de las escuelas se encontraba ubicada en casas-habitación rentadas, producto de la apropiación de la red escolar del Ayuntamiento y de las limitaciones que imponía el patrón habitacional de la capital, que se distinguía por tener una concentración histórica muy alta de la propiedad donde la mayoría de los inmuebles se alquilaban. ${ }^{11}$ La distribución de las escuelas para 1907 puede ser apreciada en el mapa 1 que muestra una marcada tendencia a ubicar los planteles en los cuarteles 1,2 y 3 , que eran las zonas más densamente pobladas. ${ }^{12}$

Si las características inmobiliarias de la ciudad dificultaban la construcción de escuelas por el alto valor catastral y la dificultad para conseguir una buena ubicación, se entiende entonces que la autoridad haya

${ }^{10}$ Véase el total de escuelas en el Boletín Mensual de Estadística Escolar, junio de 1907, en Archivo General de la Nación (en adelante AGN), Instrucción pública, Directorio de escuelas, vol. 300, exp. 31. Según el padrón escolar de 1905 había 18548 niños y 18623 niñas en la municipalidad de México, véase Boletín de Instrucción Puiblica, junio-diciembre de 1906, t. VI, p. 593.

11. Para tener una idea del patrón habitacional en la ciudad de México, véanse los estudios de Morales, "Viviendas", 2001, pp. 343-360; y Torre, Lombardo y González, "Vivienda", 2001, pp. 117-138.

${ }^{12}$ Una distribución similar puede ser comparada con el año de 1896, cuando las escuelas municipales pasaron a ser federales. Este dato evidencia que la infraestructura escolar federal estuvo basada, en gran medida, en la apropiación de la red municipal, véase Chaoul, "Instrucción", 1999, pp. 179-214. orientado sus esfuerzos por construir planteles en las municipalidades. ${ }^{13}$

Aun cuando el sentido de modernidad no se presentara en una arquitectura especializada para los establecimientos escolares elementales, se había manifestado, en cambio, en un manejo administrativo sofisticado que había permitido crear un sistema de vigilancia y control encaminado a uniformar los contenidos educativos, homologar las condiciones de la enseñanza y centralizar la información sobre los planteles en la ciudad. Este sistema tenía su fuerza en un conjunto de inspectores distribuidos en doce zonas escolares, los cuales debían ser el enlace entre las disposiciones normativas de la Dirección General de Educación Primaria y los establecimientos, así como convertirse en los ojos de la autoridad para seguir de cerca la currícula escolar, el manejo de los tiempos, los inventarios y la asistencia diaria.

Este aparato administrativo contaba además con grandes "tentáculos" que se desplegaban en cada uno de los ocho cuarteles mayores de la ciudad, a través de consejos de vigilancia. Estos dispositivos formados por el inspector de policía y dos vecinos elegidos por él tenían por cometido levantar un padrón de los niños que asistían a la escuela en cada demarcación y, con ello, cuidar el cumplimiento de la ley que obligaba a los padres o tutores mandar a los niños a la escuela.

${ }^{13}$ Edificios con características escolares propiedad nacional se encontraban cuatro en Tacuba, trece en Ixtapalapa, una en Tacubaya, cinco en Tlalpan, cinco en Cuajimalpa, una en Coyoacán, 20 en Xochimilco, seis en Milpa Alta, tres en Azcapotzalco; en Boletín Mensual de Estadística Escolar, junio de 1907, en AGN, Instrucción pública, Directorio de escuelas, vol. 300, exp. 31 . 
Mapa 1. Escuelas elementales nacionales, 1907

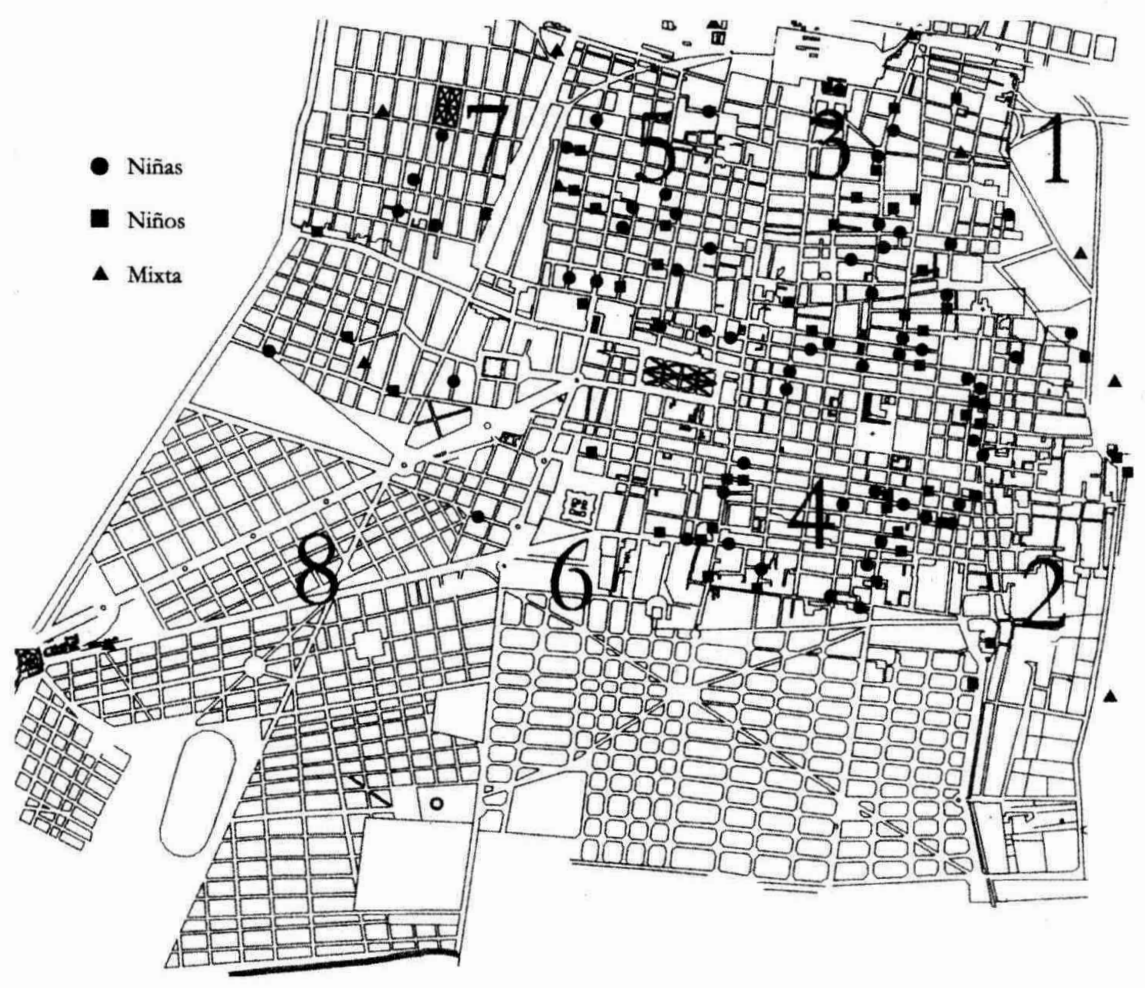

Fuente: Archivo Histórico del Distrito Federal, Instrucción pública, planos, vol. 2562. 
Los planteles elementales llamados "populares", por ser para todos, se proponían educar, instruir y dar a cada educando los elementos indispensables para saber vivir, por lo que la enseñanza, como ya se dijo, tendría que procurar ser esencialmente práctica.

La educación elemental obligatoria constaba de cuatro años de duración y los alumnos debían estar ubicados en grupos diferenciados por edades desde los seis años, los más pequeños, hasta los doce. Las materias impartidas eran: lengua nacional, aritmética, nociones de ciencias físicas y naturales, nociones de geometría, nociones de historia patria y geografía, instrucción cívica, dibujo, canto y gimnasia. Además, en las escuelas para niños se les debía enseñar la materia de ejercicios militares, y en las de niñas la de costura.

Los programas de estudio estaban organizados a partir de una progresión continua de conocimientos correspondiente a las edades de los educandos, de tal suerte que las materias eran las mismas en los cuatro años de la educación elemental, pero el grado de dificultad se incrementaba conforme se avanzaba hacia los años superiores. En ese sentido, el tiempo escolar era medido y secuencial, en el cual el avance y el progreso se certificaba mediante exámenes y el paso de un curso al siguiente.

Un seguimiento puntual de los inspectores era necesario para corroborar el control del tiempo y las condiciones de enseñanza. Que la escuela iniciara sus labores a las ocho de la mañana hasta mediodía y continuara de tres a cinco de la tarde, todos los días de lunes a viernes. El argumento para definir el horario había previsto, "que la mayor parte de los niños que van a las escuelas públicas se alimen- tan mal a causa de la escasez de sus padres, y estos niños mal desayunados ¿podrían aguantar hasta las dos de la tarde? Indudablemente no." ${ }^{14}$ Por lo tanto, cada grado escolar ingresaba con un horario escalonado disponiendo que los alumnos de primer año fueran los últimos en entrar a las 9:30. La duración de cada clase no debería exceder de los 20 minutos para los más pequeños y los 40 para los años superiores, además cada grupo estaría presidido por un profesor. ${ }^{15}$

Los directores, que habitaban en el inmueble, tenían la obligación de dar cuenta de todo el movimiento del plantel. Ellos fungieron como la figura central para el funcionamiento escolar. Sujetos a una continua auscultación por parte de los inspectores de zona y los inspectores médicos, tuvieron que rendir informes mensuales detallados sobre los alumnos, calificar el desempeño de sus subalternos y llevar a cabo los inventarios en sus planteles. Es en el marco de estos informes que entre 1902 y 1903 remitieron los planos de las escuelas y la distribución que habían hecho en cada una de ellas. Así, pues, la mirada de los profesores a través de los planos, elaborados por ellos mismos, nos permite reconstruir el lugar en el que las actividades escolares se llevaron a cabo y las posiciones que guardaron los principales actores.

En un primer acercamiento sorprende la diversidad de los planteles derivada de las propias características de las casas-habitación rentadas donde se asentaron las

${ }^{14}$ Memorias, 1883, p. 13.

${ }^{15}$ Ley Reglamentaria de Instrucción Pública Obligatoria en el Distrito Federal y. Territorios, 21 de marzo de 1891, en Dublán y Lozano, Colección, 1908, t. 10 . 
escuelas. En efecto, la heterogeneidad de la red escolar era el espejo del esquema habitacional que prevalecía en la ciudad, donde los inmuebles rentados podían ser casas solas, viviendas, accesorias, cuartos, jacales, viviendas altas, bajas y de entresuelo, en los cuales se hacía uso intensivo del espacio. ${ }^{16}$

Así, la escuela se adaptó a la trama urbanística y formó parte del escenario como un local de servicio entre tantos otros más, como la botica, la zapatería o la tienda. Los establecimientos se anunciaban hacia la calle con letreros de lienzo que indicaban el número de plantel para niños o niñas, y su permanencia en la zona podía ser temporal debido a las condiciones del contrato de arrendamiento. En ese sentido, la escuela elemental reflejó la misma movilidad que la ocupación de los espacios habitacionales en la capital y, por lo general, no fue un espacio público que evidenciara su importancia por tener un edificio propio o ser un referente cultural en el cuartel o la manzana.

Los letreros de los establecimientos donde operaban las escuelas no marcaban una separación clara entre la interacción cotidiana de afuera - del transitar por la calle- con el movimiento interior, pues por disposición de las autoridades la puerta debería estar abierta y permitir la entrada de los alumnos a cualquier hora. $\mathrm{La}$ misma ley reglamentaria de 1896 consignaba que la obligación de asistir a las escuelas imponía el deber de recibir a los alumnos cuando se presentaran. ${ }^{17}$ Se tra344-345.

${ }^{16}$ Véase Morales y Gayón, "Viviendas", 2001, pp.

17 Archivo Histórico del Distrito Federal (en adelante AHDF), Escuela elemental 89, vol. 2555, oficios y comunicaciones. Véase Ruiz, Tratado, 1900, p. 179. taba de espacios disponibles al paso de los niños y a la mirada de la autoridad escolar. Como se verá más adelante, esta naturaleza abierta de la escuela distaba mucho de ser un modelo de vida escolar cercada, cuyas fronteras cerradas podían generar un poder disciplinario y un control preciso de los tiempos y espacios.

Una vez concluido el periodo de inscripciones previsto en el calendario escolar, que era del 15 de diciembre al 6 de enero, se iniciaban los cursos. Entonces, los directores tenían que remitir a los consejos de vigilancia de cada cuartel los niños que estuvieran inscritos y los que lo iban haciendo a lo largo del año. Las vacaciones de noviembre y diciembre habían llegado a término y los hijos de albañiles, carpinteros, comerciantes, sirvientas, pintores, tipógrafos, joyeros, jardineros, artesanos, encuadernadores y empleados, entre otros, se preparaban para asistir de manera obligatoria a las escuelas elementales. $^{1.8}$

Aun cuando la normatividad impelía a los padres a mandar a sus hijos a clases, la fluctuación en la asistencia fue una constante. Los médicos ya habían dado cuenta de este hecho, pues a decir de ellos: "se observa que muchos padres no envían a los niños a la escuela y los que los envían, lo hacen durante un tiempo que siempre es pequeño, porque desean, cuanto antes, utilizar los servicios de estos pequeños". ${ }^{19}$

${ }^{18}$ AHDF, Escuela elemental 256, vol. 2559, y Escuela elemental 16, vol. 2537 , en estos volúmenes se encuentran algunas muestras de las hojas de registro que incluye la profesión y domicilio de los padres.

${ }^{19}$ Memorias, 1883, p. 160. 
Lanny Thompson, en su estudio, propone que las familias de las clases populares en la ciudad de México, durante el porfiriato, tenían que recurrir a la fuerza de todos sus miembros para poder sobrevivir y los niños contribuían al ingreso familiar a partir de los doce años, aunque muchas veces tenían que hacerlo antes de esa edad.

Según Thompson, los hogares que podían establecerse únicamente con el ingreso del padre de familia lo hacían porque éste contaba con un empleo que tenía un cierto grado de capacitación, el cual le permitía sobrepasar el nivel de pobre$\mathrm{za}^{20} \mathrm{Si}$ se sigue esta propuesta, es probable que los alumnos que asistían de forma regular a la escuela fueran hijos de padres con empleos estables, y la falta de asistencia estuviera relacionada con la movilidad del empleo del jefe de familia, con la inestabilidad en el domicilio y con el trabajo de los hijos.

De una muestra representativa de 24 planos de establecimientos elementales, ciertos rasgos me permiten agrupar los planteles en la ciudad de México en tres categorías: escuelas extensivas, escuelas en la vecindad y escuelas diferenciadas. ${ }^{21}$ La distribución de las escuelas analizadas puede ser apreciada en el mapa 2. Mientras las escuelas extensivas y de vecindad se ubican en la parte oriente y sur de la ciudad, las diferenciadas se encuentran en la parte poniente conformada por los nuevos fraccionamientos.

${ }^{20}$ Véase Thompson, "Artisans", 1998, pp. 307-324.

${ }^{21}$ Los planos que se analizaron corresponden a las escuelas elementales: $19,25,28,29,41,42,43,47$, $53,58,59,62,65,66,67,68,72,75,77,89,94$, $108,109,126$.

\section{ESCUELAS EXTENSIVAS}

Al remitir los planos, los directores presentaban los documentos como "Plano de la casa que actualmente ocupa la escuela". La referencia no sólo hacía alusión a un sentido de temporalidad, pues estas escuelas como tantas otras tenían una ubicación que, como ya se dijo, estaba relacionada con la renta de las casas o los requerimientos de amplitud. También el que là escuela "ocupara" la casa implicaba que la llenaba o se apropiaba de ella.

Los establecimientos que yo llamo extensivos literalmente "llenaron" el espacio de la casa habitación y la modificaron para funciones educativas, o bien la hicieron crecer en razón de los nuevos requerimientos espaciales. ${ }^{22}$ Ciertos arreglos permitieron sustituir algunas áreas y añadir, a la estructura original de la casa, unas divisiones para ubicar salones de clase. De esta manera, el espacio para las aulas se "abría" o se creaba en cubos de luz, patios y pasillos en función del número de alumnos que asistieran.

La forma en que se fueron extendiendo - a lo largo del tiempo- de manera indiferenciada y poco ordenada permite observar cómo en estos planteles se entremezcló la vida familiar del director con la escuela. Ambos mundos, apenas divididos entre sí con fronteras porosas, dan la impresión de una utilización expansiva del espacio, a tal punto que no se advierte dónde empieza uno y dónde termina el otro. Aulas colindantes con las recámaras, con el comedor o con la cocina -como si

${ }^{22}$ Algunos establecimientos de este tipo son las siguientes escuelas: $19,41,43,58,67,68,77,89$, 94,126 . La superficie promedio de los inmuebles era de 300 metros cuadrados. 
Mapa 2. Escuelas muestra, 1902 (categorías)

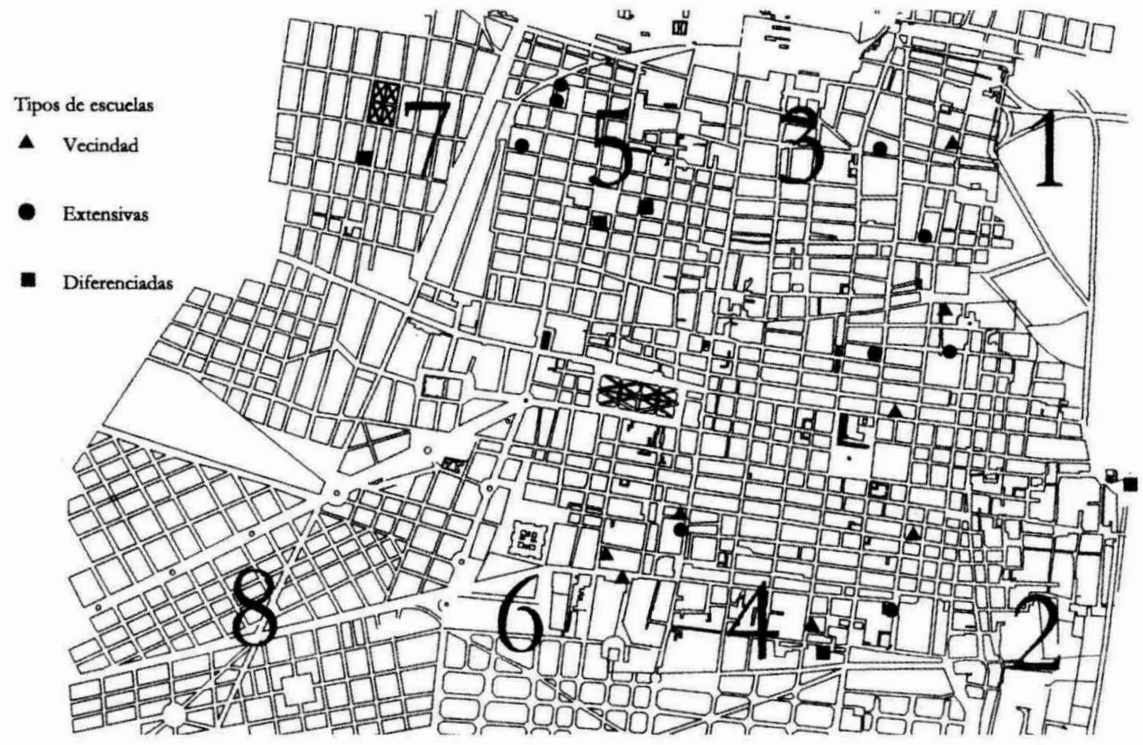

Fuente: Archivo Histórico del Distrito Federal, Instrucción pública, planos, vol. 2562. 
la parte funcional de la escuela estuviera resguardada por espacios de vida- comprometían el desarrollo autónomo de las clases y las actividades de los que ahí habitaban (véase plano 1).

Es común encontrar en estas escuelas divisiones que valorizaban el espacio escolar en función de la simbolización del salón de clase como lugar. Así, las aulas se definían frente a otros cuartos de la casa mediante el mobiliario. Una mirada en su interior permitía apreciar la mesa del profesor en cuya cubierta de paño estaba colocado un timbre y detrás de él una silla de mimbre. A lo largo de las paredes, por lo general, había mapas de la república mexicana, del Distrito Federal y del mundo. En un extremo, una cómoda con llave servía para guardar útiles y los instrumentos de química y física. Hacia la entrada, un perchero estaba dispuesto para que los niños pudieran colocar sus capas y sombreros al entrar al salón. Las bancas, que eran de tipo binario, estaban alineadas y colocadas frente al profesor. Además, había dos o tres pizarrones de lienzo con sus respectivos caballetes, que podían moverse hacia cualquier parte del aula para que los niños pudieran seguir la lección. Finalmente, un reloj de pared daba sentido al ambiente. ${ }^{23}$

La irregularidad en la asistencia hacía que los salones de clase tuvieran una cierta flexibilidad en su disposición para recibir, a lo largo del año, un número variable de educandos. Las aulas de primer año en las escuelas extensivas -y en las demás como se verá después- eran las más densamente pobladas, pues contaban con una asistencia promedio que podía variar de 40 a 70

${ }^{23}$ AHDF, Escuela 126, inventarios, vol. 2558, y Escuela 43, inventario de muebles y útiles, vol. 2544. alumnos. Salones, con un área de 30 metros cuadrados, se veían reducidos a lo largo del día o del mes por el incremento del tamaño del grupo. Contrario a lo dispuesto por los higienistas que proponían una superficie de dos metros cuadrados de separación entre alumnos para evitar la aglomeración, las aulas ofrecían una superficie a veces de hasta 30 centímetros cuadrados por estudiante. ${ }^{24}$ Además, si bien la intención de las autoridades era diferenciar los grados escolares por edades, lo cierto es que para principios del siglo Xx este lineamiento no se llevaba a efecto, pues lo mismo había alumnos de cinco a doce años en primer grado, que estudiantes de nueve a 16 años para cuarto.

Estos lugares, por lo tanto, no sólo se enfrentaban a una mezcolanza de niños, sino que frecuentemente hacían falta bancas, libros y útiles, lo que lleva a pensar en la dificultad que representó para el profesor asignar tareas, mantener el orden, lograr una vigilancia y sujetarse a una rutina basada en el tiempo que ordenaba la autoridad. En ocasiones era común encontrar salones subdividios para atender dos grupos al mismo tiempo y entonces

dos profesores esfuerzan a un mismo tiempo la voz, alumnos que contestan preguntas diferentes [...], alteraciones del orden o de disciplina que se comenten en un grupo y que influyen en las labores del que está junto. 25

${ }^{24} \mathrm{El}$ dato fue obtenido al calcular el área de los salones de clases del primer año de las escuelas 126 y 47 entre el número de alumnos que reportaron los directores en 1903. AHDF, Escuela elemental 126, vol. 2558, y Escuela elemental 47, vol. 2544.

${ }^{25}$ Memorias, 1883, p. 34. 


\section{SECUENCIG}

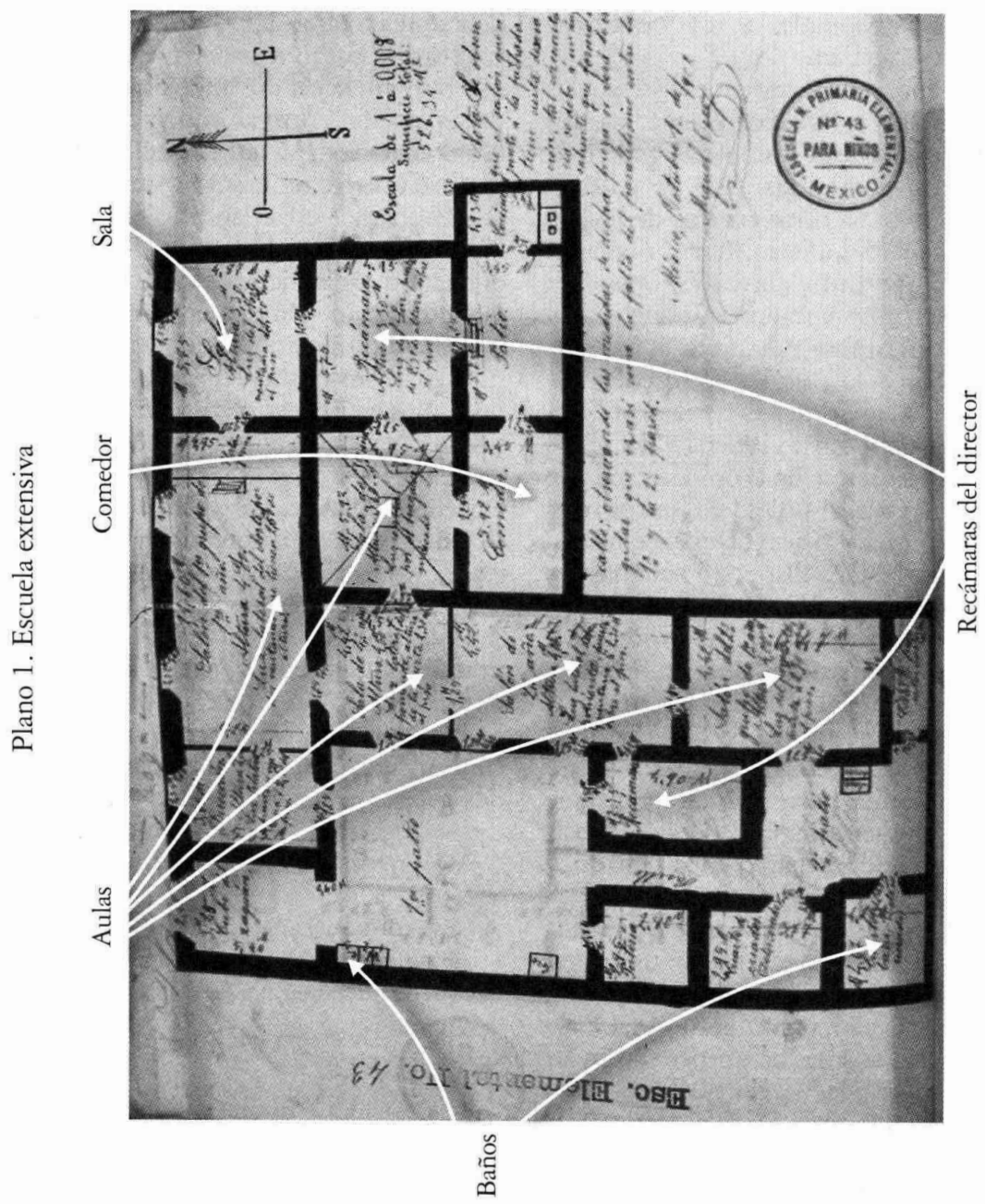

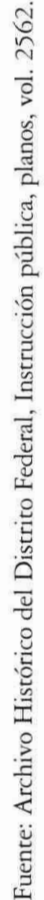


Apegarse a la disciplina propuesta por la autoridad implicaba que en las horas de clase los alumnos "hablarán únicamente cuando el maestro lo indique", o bien, manejar los tiempos de los ejercicios escolares con el uso del timbre como toques de corneta y tambor a manera de los militares. ${ }^{26}$ Resultaba por demás complicado entender cómo se podía llevar a cabo esta dinámica en las aulas donde tres niños compartían una banca binaria, o donde muchas veces no alcanzaban las pizarras para seguir los ejercicios que ponía el profesor en el pizarrón. La asignatura de nociones de ciencias físicas y naturales, que se debía enseñar con los pequeños museos escolares, "ricos en objetos de poco valor y abundantes en cosas de aplicación diaria", implicaba un esfuerzo muchas veces infructuoso del profesor para que, por ejemplo, un murciélago, un pájaro, una serpiente, una colección de insectos (como reportan los inventarios) estuvieran siempre en manos de los niños, como la autoridad disponía, y pudieran aprender con base en la observación.

En los salones de clase para tercer y cuarto años no sólo la ausencia de jóvenes y niños dificultaba cubrir el programa, sino que las aulas, con un área de 16 metros cuadrados en promedio, eran las más pequeñas. Muchas veces carentes de luz y ubicadas en los espacios más alejados del inmueble acogían grupos con pocos estudiantes (entre seis y 17 alumnos), cuyas edades podían variar de los diez a los 15 años.

Para atenuar el grado de incerridumbre y confusión que imperaba en la escuela, uno de los controles disciplinarios que los maestros emplearon fue el apren-

${ }^{26}$ Véase Ruiz, Tratado, 1900, p. 197. dizaje intensificado, multiplicado, usando la repetición para mantener el orden. "Se reducía la enseñanza a una lista de preguntas que la maestra dirigía a los niños y a otra lista de respuestas que ya los niños también sabían de memoria." Si bien el reglamento prescribía que el castigo debía ser gradual comenzando con la reprobación por medio de la mirada, hasta llegar a detener al alumno en la escuela después de clase o bien la expulsión por quince días o definitivamente, los alumnos se disciplinaban según fuera el criterio del maestro. ${ }^{27}$

Generalmente, en las escuelas extensivas encontramos que la división del espacio se pensó en función de la jerarquía en el interior del plantel. En la distribución jerárquica de estos establecimientos había un salón principal donde impartía clases el director. En él se observa una mejor iluminación, mayor amplitud y una disposición especial en un lugar referido hacia la calle que lo exponía a la mirada del exterior. Ese espacio dominante destinado al ejercicio de la autoridad se contraponía con otros subordinados, estrechos, sin luz, poco ventilados donde se ubicaban los demás salones de clase. Es común que las habitaciones con las mejores condiciones

${ }^{27}$ Castellanos, Organización, 1897, pp. 129 y 184. Relatos del castigo en la escuela, como el de Ángel de Campo, "Micrós", pueden revelar cuál podía ser ese criterio: "aquel cuarto húmedo y oscuro, Ileno de sillas rotas, tinas desfondadas y ropa sucia, donde paseaban las ratas del tamaño de un conejo. Había alacranes y mestizos, que acobardaban a los más valientes; era preferible dar 100 líneas del Urcullu, estar media hora hincado y en cruz, hasta recibir la orden de que no le dieran dulce y fruta en su casa, a entrar a aquella pieza que olía a ropa sucia y a humedad”. Ángel de Campo, “PPobre viejo!”, en Campo, Cuentos, 1944. 
dentro del inmueble fueran destinadas al uso personal del director y el resto a la escuela.

El lugar de encuentro, como el patio de juegos, fue generalmente acotado en función de la necesidad de más salones; lo que inducía a que muchas veces fueran las aulas los lugares de socialización y de intercambios.

Todos estos planteles compartieron un difícil acceso al área de servicios, que se ubicaba en la parte más alejada de la casa y se distinguía por tener dos o tres baños a disposición de los 200 niños que asistían en promedio a este tipo de escuela. Los servicios podían consistir en excusados de tipo inglés, que contaban con un tanque lavador, o bien, de tipo colectivo, en la que se vertía la materia en un gran canal de alta pendiente en cuyo término había un sifón, también podía ser la fosa fija dispuesta en las escuelas ubicadas en los barrios más pobres y apartados de la ciudad. Baños que, a decir de los reportes de la época, presentaban un foco de infección e imprimían un ambiente de fetidez que infestaba todo el edificio ${ }^{28}$ (véase plano 2).

El ejemplo más representativo de los establecimientos que entremezclaron rasgos de domesticidad con los escolares es el edificio en el que se encontraban las elementales número 19 para niños y número 68 para niñas. Estas escuelas, dirigidas por el matrimonio de los profesores Lizárraga, muestran cómo convivieron ambos planteles en el mismo inmueble. En el plano que los directores remitieron, los espacios fueron asignados siguiendo la misma jerarquización de los papeles en la familia: las clases para los niños fue-

${ }^{28}$ AGN, Secretaría de Instrucción Pública y Bellas Artes, Anales de higiene escolar, 1910, caja 285, exp. 18. ron dispuestas en las mejores aulas, con buena iluminación y al frente del edificio con vistas a la calle, en tanto que las clases de las niñas fueron ubicadas al fondo del inmueble, en aulas más pequeñas y contiguas a las áreas de tránsito por donde se accedía a los servicios de la casa. Así, el lugar del trabajo docente del director se encontraba en un primer plano y expuesto públicamente, en tanto que el ámbito del desempeño de la directora era un espacio secundario que se vinculaba al comedor y a la cocina de la casa. ${ }^{29}$

\section{ESCUELAS EN LA VECINDAD}

A pesar de que higienistas y pedagogos habían reiterado que las escuelas no deberían estar ubicadas en casas de vecindad, muchos planteles se adaptaron al esquema de estas construcciones que imperaba en la parte central y sur de la ciudad, que eran las más densamente poblada.

Estos edificios tenían estructuras lo suficientemente flexibles para hacer un uso intensivo del espacio y ofrecer diversas opciones en un mismo inmueble, ya sea para habitaciones o locales de servicio, según fuera la disponibilidad económica de los inquilinos. ${ }^{30} \mathrm{La}$ escuela, tan moldeable como el espacio con el que interactuó, se ubicó entre cuartos, accesorias, viviendas bajas y de entresuelo.

Generalmente dispuestos en la vivienda alta, los establecimientos escolares ocu-

${ }^{29}$ AGN, Secretaría de Instrucción Pública, Directorio de escuelas, 1907, vol. 300 , exp. 31.

${ }^{30}$ Según las investigaciones de Torre, Lombardo y Gónzalez, "Vivienda", 2001, pp. 117-138, y Morales, "Viviendas", 2001, pp. 343-360. 


\section{SECUENCIA}

Plano 2. Escuela extensiva

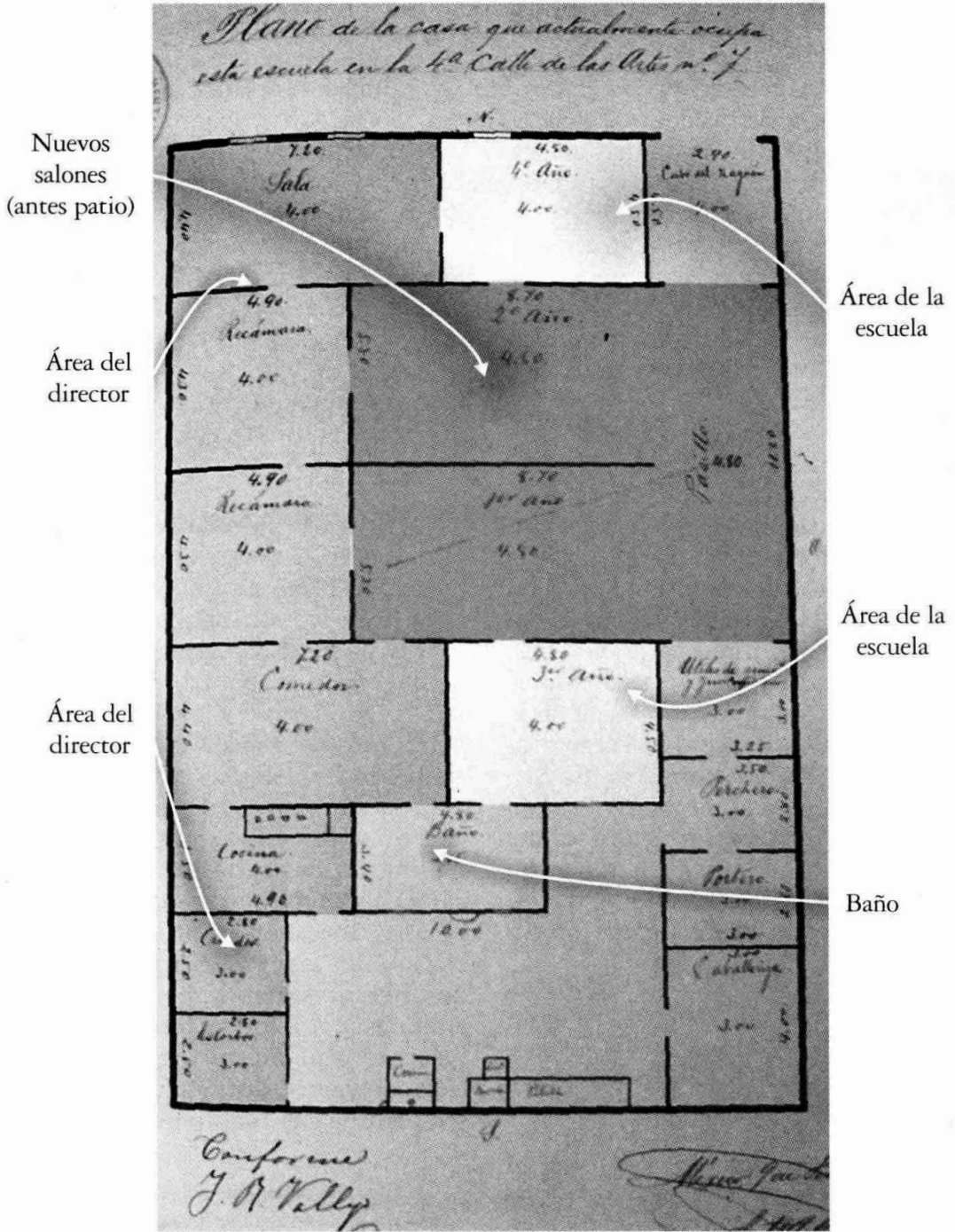

Fuente: Archivo Histórico del Distrito Federal, Instrucción pública, planos, vol. 2562. 
paban un lugar preferente dentro del inmueble, pues contaba con varios cuartos que se utilizaban para las aulas y para las habitaciones del director. A veces los planteles contaban con servicios integrados y vista a la calle, y en ocasiones los espacios eran más grandes que las demás viviendas. ${ }^{31}$ Sin embargo, por su disposición, el acceso de los niños a los salones de clase implicaba que éstos recorrieran el patio central, subieran por la escalera y se desplazaran por los pasillos todos los días a diferentes horas, movimiento que se convertía en una intromisión continua para los propios vecinos.

Por su emplazamiento dentro del edificio, las escuelas de este tipo superpusieron tres espacios en un mismo tiempo: el de la actividad escolar, el de la intimidad del director y el del movimiento del resto del inmueble conformado por los inquilinos de las viviendas bajas y de entresuelo. Planteles ruidosos que compartían el ajetreo diario, la rutina de los que ahí habitaban y la proximidad de otros adultos ajenos a la vida escolar hacen pensar en una ordenación compleja. Es probable que algunos alumnos vivieran en el mismo edificio y la escuela resultara un alargamiento de su vida familiar. En ese sentido, el ámbito de interacción escolar tendría, entre otros referentes, vincu-

${ }^{31}$ Morales, "Viviendas", 2001, p. 345. Rodríguez Piña propone una tipología de las viviendas en 1811 que para los años del pofiriato puede ser tomada en cuenta en sus consideraciones generales. Para este autor, entre las diversas viviendas que componían una vecindad se lograba una integración residencial que no evitaba la segregación vertical. La vivienda principal obedecía a un mayor estatus, en tanto que los altos y los cuartos bajos correspondían a uno menor. Véase Rodríguez, "Vecindades", 1976, pp. 68-96. laciones por la proximidad vecinal y de parentesco con los que ahí habitaban.

Ajustados al mismo horario y calendario como el resto de los establecimientos de la ciudad, los planteles en las vecindades tenían, sin embargo, un patrón de asistencia fluctuante más marcado, probablemente porque la mayoría de los niños que habitaban en esas zonas tenían padres cuyos empleos necesitaban del apoyo laboral de sus hijos. A diferencia de los planteles extensivos, muchas veces habia menos salones de clase para acoger a un promedio de 150 alumnos y no se establecía una división clara por grupos y edades para los distintos grados escolares. ${ }^{32} \mathrm{~A}$ decir de Luis E. Ruiz,

en las casas de vecindad las habitaciones son más reducidas, en menor número y en peores condiciones. Repartidos los departamentos entre la familia del profesor y los alumnos, quedan todos incómodos y llenos de dificultades. ${ }^{33}$

Dentro del espacio de la escuela, la simbolización del salón de clases se vuelve a encontrar a través del mobiliario: un escritorio y una silla de mimbre así como un timbre para el profesor, un estante con cómoda para el museo escolar y bancas binarias dispuestas en filas para seguir la lección. En las paredes, una exposición de diferentes mapas, perchas para los alumnos y el reloj conformaban el ambiente escolar. Sin embargo, la significación del lugar se distinguía porque en estos planteles el mobiliario era usado y

${ }^{32}$ AHDF, Escuela elemental 47, vol. 2544. En el expediente se presentan las cifras de asistencia de esta escuela de vecindad desde 1898 hasta 1910.

${ }^{33}$ Memorias, 1883 , p. 29. 
antiguo, pues había pizarrones rotos, mapas gastados y sillas viejas. ${ }^{34}$

Niños amalgamados de diferentes edades hacían que la superficie de las aulas de 20 metros cuadrados, en promedio, se viera reducida en razón de la propia asistencia, la cual podía fluctuar entre 30 a 60 alumnos a lo largo del mes. Por ello, una petición recurrente de los directores era hacer "crecer" estos espacios:

Tengo la honra de comunicar a usted que la asistencia de la escuela a mi cargo ha aumentado y que la pieza en que actualmente se halla dicho grupo no es suficiente para los alumnos que concurren. Por lo que atentamente suplico a usted se digne dar sus respetables órdenes a fin de que se quite el tabique que media entre la sala de clases y la cocina, quedando así en bien de los alumnos un salón de nueve metros ochenta centímetros. ${ }^{35}$

Aulas comunicadas, ventiladas e iluminadas a través de los pasillos hacen pensar en una falta de orden que impedía cumplir con el programa y en la ausencia de autonomía entre los mismos salones y el resto del inmueble.

En ocasiones, el cuarto año era inexistente no sólo por falta de estudiantes, sino también por la indisponibilidad de espacio dentro del propio edificio. Tampoco encontramos un lugar asignado para la dirección escolar, por lo que en estos esta-

${ }^{34}$ Para 1908 mientras una escuela extensiva tenía un inventario valuado en 2500 pesos en promedio, para las escuelas en las vecindades era de 1500 pesos. AHDF, Escuela elemental 47, vol. 2544, y Escuela elemental 126, vol. 2558.

${ }^{35}$ AHDF, Instrucción pública, Escuelas elementales, vol. 2531, exp. 185-210. blecimientos la simbolización de la autoridad se presentaba de manera difusa. Incluso las habitaciones del director eran más compactas pues, a diferencia de las escuelas que se encontraban ubicadas en casas solas, no contaban muchas veces con estancias como sala y comedor para uso personal.

En estas viviendas, la escuela como lugar se diluía en un ambiente que imponía sus propios ritmos, ya que no disponía de áreas de recreación especiales para los niños. Las azotehuelas funcionaban a manera de patios y eran espacios compartidos con el resto de la vecindad, lo que dificultaba que los alumnos jugaran e hicieran los ejercicios de gimnasia o militares. Lo mismo sucedía con el área de servicios, pues los excusados, ubicados en la planta baja del edificio, eran utilizados por los estudiantes y los demás inquilinos. En la integración vertical del inmueble, la escuela misma podía ser un lugar de tránsito para acceder a otras partes del edificio.

Según lo manifestaba Ruiz:

[En la vecindad] la vida íntima del profesor, como la de los vecinos, está siempre con todas sus inconveniencias ante los niños naturalmente curiosos y observadores: de aquí el mal ejemplo, la pérdida de tiempo, la falta de respeto y otras mil dificultades que sería prolijo enumerar, graves tratándose de los departamentos interiores, irremediables en los de uso común como, por ejemplo, los patios a donde los niños no pueden concurrir, careciendo de ejercicio, de los juegos que deben considerarse como una de las más imperiosas necesidades de la educación. ${ }^{36}$ (Véase plano 3).

${ }^{36}$ Memorias, 1883, p. 29. 


\section{SECUENCIG}

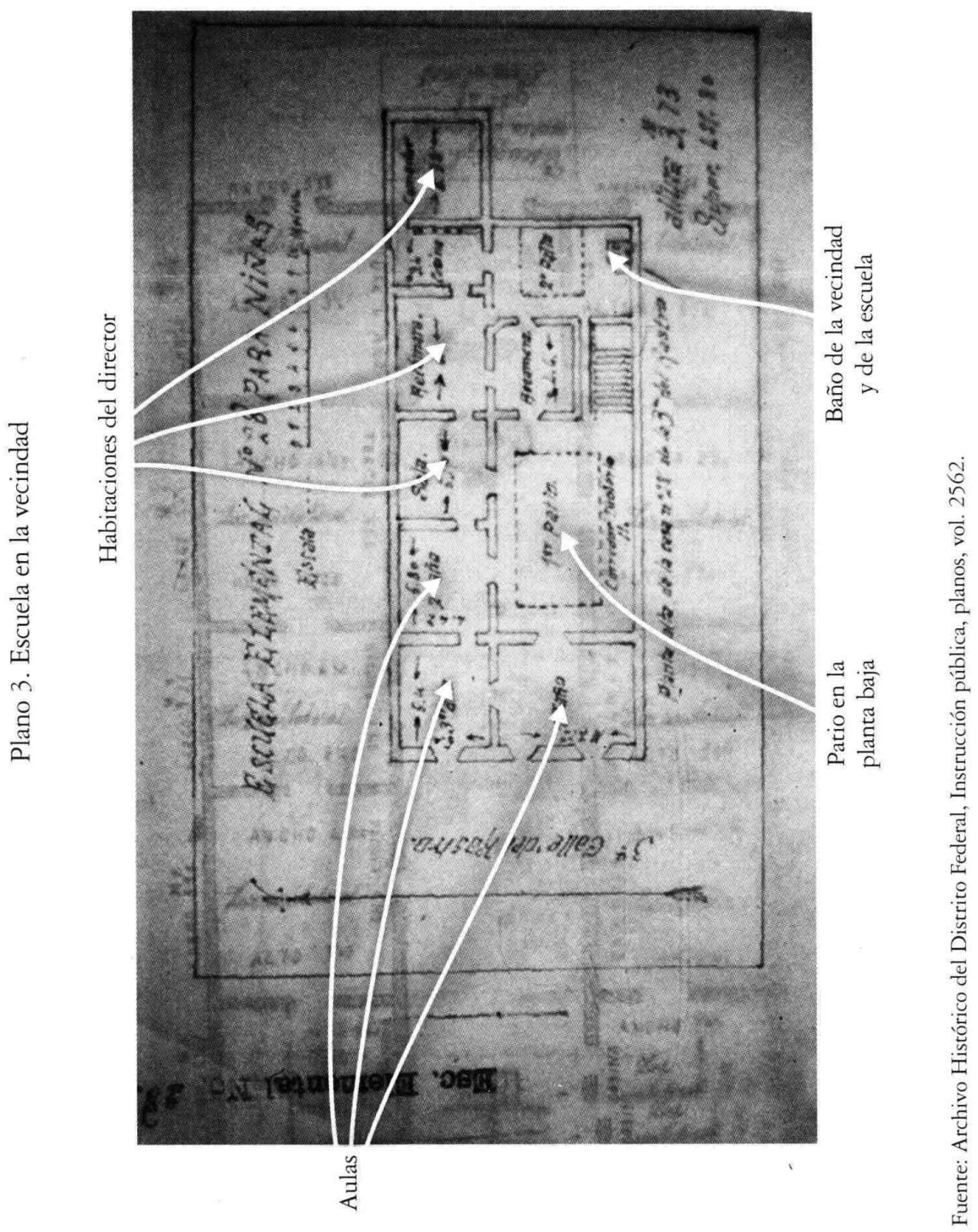


Ahora bien, si seguimos de cerca las características de las escuelas extensivas y las de vecindad, podemos afirmar que en la mayoría de ellas los espacios estuvieron comunicados por la luz, de tal suerte que las puertas no podían estar cerradas, pues impedían la iluminación de los salones de clase. Por lo tanto, significa que estos planteles fueron espacios donde los flujos de ruidos y personas eran una constante. La luz convirtió a las aulas en lugares de tránsito y propició también la porosidad entre los ambientes privados del director y los públicos de la escuela. ${ }^{37}$ Esto originó que los salones, carentes de iluminación, fueran también ambientes poco ventilados en los que, según los reportes, había una "atmósfera mal oliente debido a la concentración de exhalaciones humanas". ${ }^{38}$

La escasez de luz influyó en una falta de ordenación y, por consiguiente, en que la división del tiempo y los trabajos escolares que imponía el programa no se llevaran a efecto. El tiempo calculado y administrado por la autoridad, que debía

\footnotetext{
${ }^{37}$ El doctor Andrés Benavides, médico inspector de escuelas primarias, opinó: "Es cosa corriente encontrar que la superficie de los salones de enseñanza no tiene la proporción debida con la de las puertas y ventanas que los alumbran y los ventilan. De las casas que no pertenecen a la federación hay algunas muy bien acondicionadas para escuelas, como la 71 y la 87; pero muchas son inaceptables en absoluto, ora por su estrechez, ora por el corto número de piezas utilizables para clases, ora por las habitaciones o bodegas vecinas a la escuela en la propia casa, ora por la falta de luz en los salones, y en esto último se ve el caso que si se oyese referir no se creería (Escuela Francisco J. Clavijero), de que todo el día sea indispensable alumbrar artificialmente las piezas, con gran perjuicio para la salud de los educandos", en AGN, Anales de higiene escolar, 1910, caja 285, exp. 18.

${ }^{38}$ Ibid.
}

regir los relojes colocados en las aulas, no era efectivo. Antes bien, el reloj fue una simbolización del espacio que le confería valor al salón de clases como espacio, más que determinar o marcar las rutinas de las labores escolares con un horario prescrito (véase plano 4).

Las zonas de recreación fueron, por lo general, las azotehuelas y los patios de las casas, y en ellos podemos encontrar una superficie por alumno que variaba entre medio y un metro cuadrado por niño, cuando el ideal que marcaba la Dirección General de Educación Primaria era un espacio cubierto y uno descubierto con una superficie de seis metros cuadrados por alumno.

Por lo reducido de los patios, algunas actividades escolares, como los ejercicios militares que marcaba el plan de estudios, no siempre contaron con un lugar asignado en el inmueble. Para la autoridad, estos ejercicios cubrían una importancia crucial, pues "el niño de la escuela elemental no es solamente un futuro obrero, sino también un ciudadano en perspectiva, que acaso deberá ser un futuro soldado", por lo tanto, los batallones escolares no eran simplemente un juego de niños, sino un importante asunto útil y patriótico que debería lograr que los alumnos de cuarto año llegaran a desarrollar la destreza necesaria para manejar un fusil. ${ }^{39}$

No obstante, a falta de disposición espacial, la flexibilidad de las escuelas influyó para que éstas "salieran" y se apropiaran de las plazas de la ciudad. Y así,

${ }^{39}$ Véase Ruiz, Tratado, 1900, p. 144. Ruiz aclara que este programa podía realizarse gracias a que ya se contaba con fusiles escolares con el sistema Máuser traídos expresamente por orden del presidente de la república. 


\section{SECUENCIG}

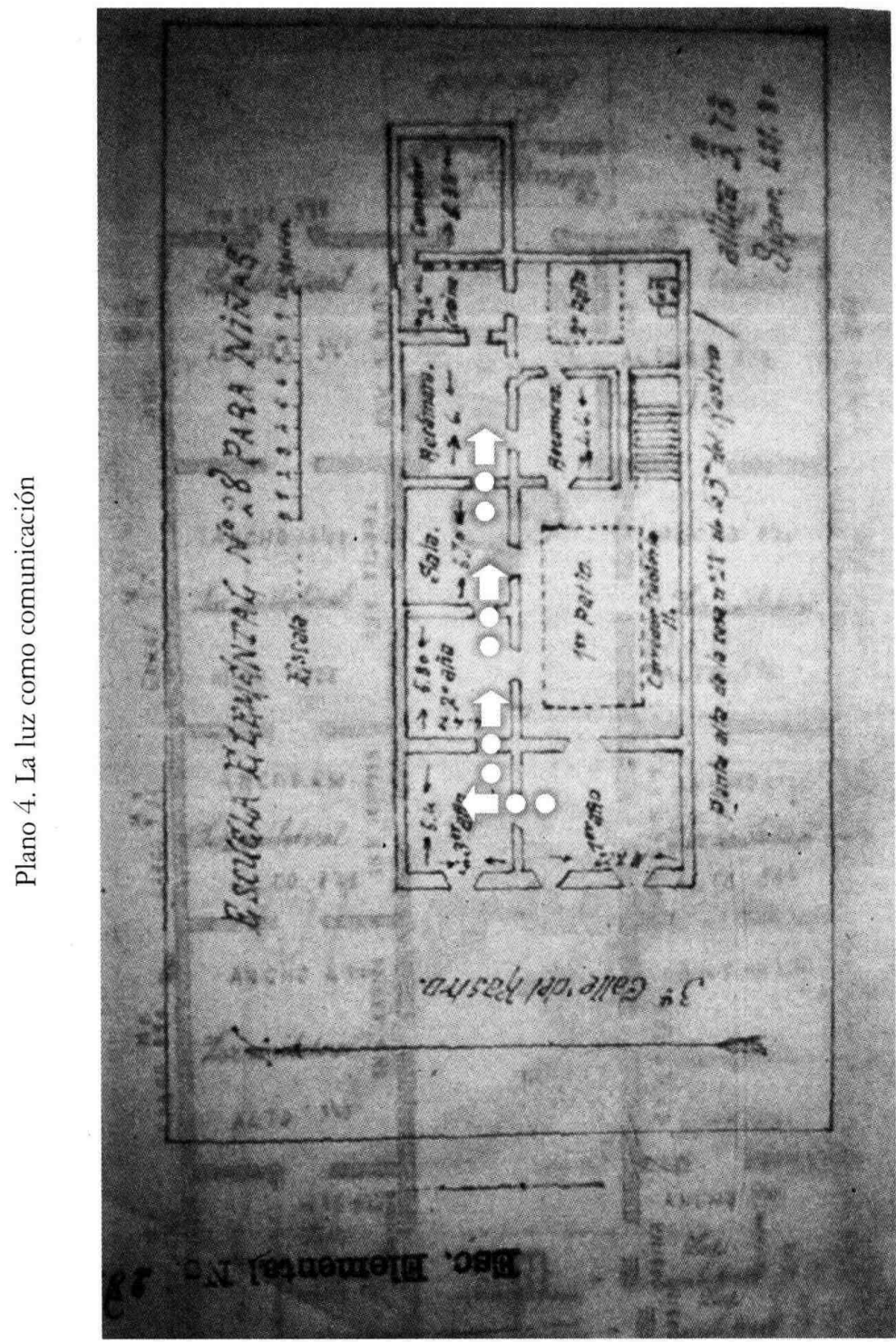




\section{SECUENCIA}

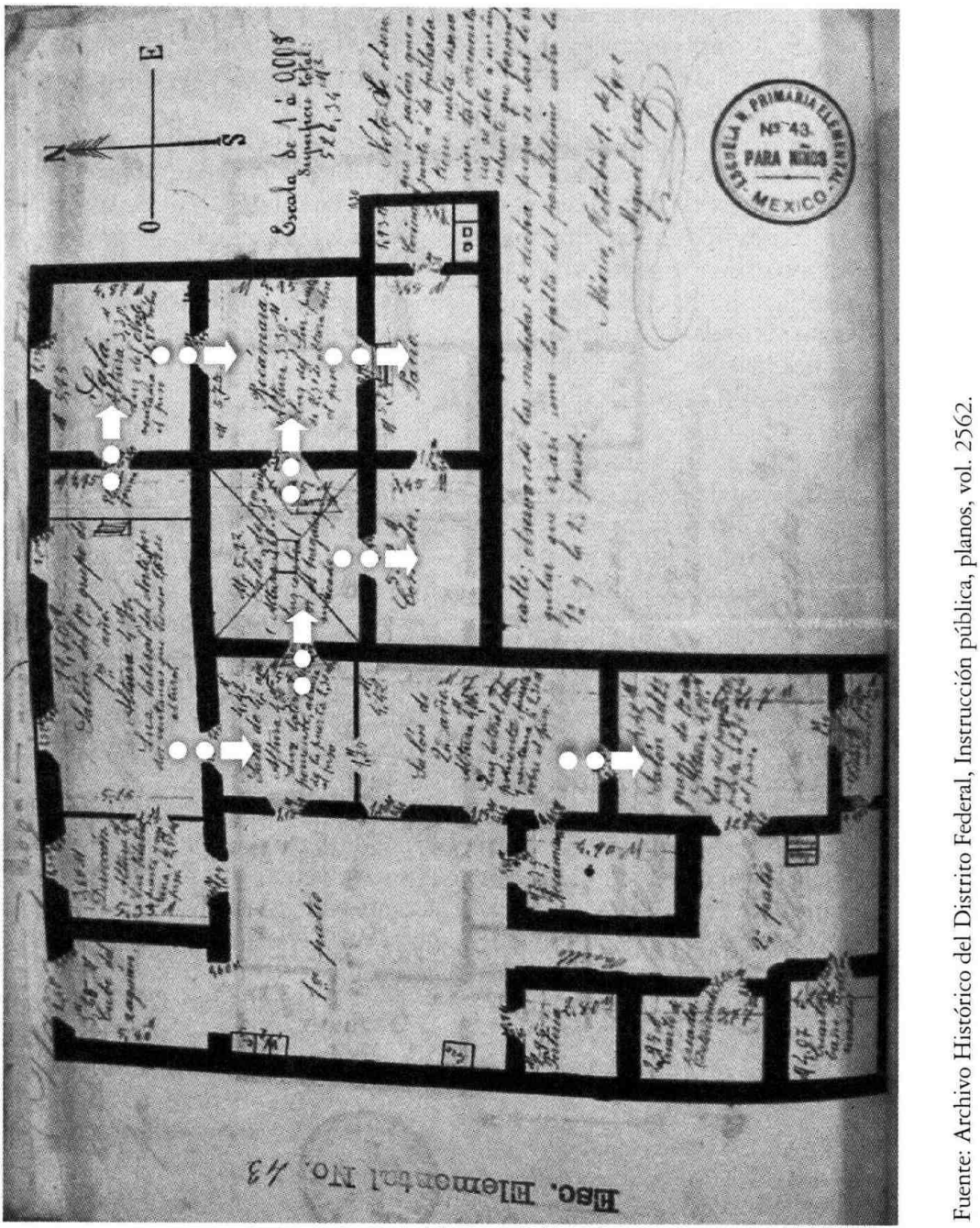


la plaza de Santiago Tlatelolco, la de Tecpan de San Juan, o bien la del Árbol -según la zona donde estuviera el establecimiento- sirvieron como escenarios de la educación militar de los niños. ${ }^{40}$

Aunque los maestros remitían mensualmente información sobre sus inventarios e incluían material del museo escolar, del gabinete de física y de la biblioteca, en los planos no existe un registro que indique su posicionamiento como un lugar especializado, lo que hace suponer que fueron espacios secundarios adscritos a los mismos salones de clase, guardados bajo llave en estantes o en la misma dirección de la escuela.

Según las especificaciones de los higienistas, cada escuela debía contar con un lavabo y agua limpia, jabón, toalla, peine y cepillo para recibir a los niños. Ello, con el fin de que los alumnos adquirieran el hábito del aseo. ${ }^{41}$ Sin embargo, el área de servicios en estos planteles fue completamente marginal. Los inventarios escolares sólo reportan un aguamanil en cada aula, y si los alumnos querían tomar agua debían hacerlo con un solo vaso de peltre disponible para todo el salón de clase. ${ }^{42}$ El problema se agravaba además por la carencia de agua en los planteles, tanto para beber como para el aseo de los excusados. Según el informe de la inspección médica, los propietarios de los inmuebles se negaban a hacer desembolsos para introducir el agua de la ciudad o para perforar pozos artesianos, y muchas

${ }^{40}$ Oficio de la noticia sobre la instrucción militar, 29 de abril de 1903, en AHDF, Escuela elemental de niños núm. 89, vol. 2555.

${ }^{41}$ Véase Ruiz, "Cartilla", 1903, p. 170.

42 AHDF, Escuela elemental 47, vol. 2544, inventarios de los años 1899-1910. veces se encontraron con el problema de que el agua que bebían los niños no era potable. ${ }^{43}$ El escaso número de baños y su difícil acceso hacía que los inspectores informaran:

cuando las niñas se sirven de los excusados quedan sin lavado entre el uso que hace de ellos una alumna y el de la que la sigue, hasta que la humilde maestra, con desdoro de su dignidad y con el asco natural que provocan las inmundicias, va a soltar el agua de las cajas para suprimir la fetidez que infesta todo el ambiente del edificio. ${ }^{\text {di }}$

Muchas veces si se trataba de una escuela que operaba por la mañana como elemental y por las noches como nocturna, a los ojos del inspector le parecía que "la sífilis y la blenorragia hacían víctimas inocentes a las niñas" que eran contagiadas por enfermedades de adultos a través de los baños. ${ }^{45}$ En casos extremos, si el inmueble contaba con accesorias en la entrada, los inquilinos tenían permiso del propietario para usar los baños y el agua del plantel.

Una imagen de apiñamiento tanto en los salones como en los patios y en los baños hace pensar que los actores que interactuaban en estos espacios escolares tenían clara conciencia de su proximidad. Si se considera que el patrón habitacional en la ciudad se caracterizaba por tener una alta densidad residencial, la tolerancia hacia la presencia de otros en un espacio reducido era un referente cotidiano. Como algunos observadores daban cuenta: "[En

${ }^{43}$ Véase Boletín de Instrucción Pública, abril-mayo de 1911, t. XVII, p. 126.

${ }^{44}$ lbid.

${ }^{45}$ lbid. 
los cuartos de vecindad] yacen amontonados el padre, la madre, los hijos de todas las edades y sexos, y otras muchas personas más, extrañas a la familia. Allí todo se hace en presencia de todos." ${ }^{46}$ Se puede inferir, dadas las características del espacio escolar, que las escuelas extensivas y de vecindad se ajustaban a ese patrón.

\section{ESCUELAS DIFERENCIADAS}

A manera de excepción, y no de regla, en algunos planteles elementales el espacio escolar representó un lugar casi cerrado, es decir, se encuentra una clara división entre el ámbito privado de la vida familiar del director y el público escolar. No se observa que se hayan entremezclado las aulas con las habitaciones, ni que los salones de clase hayan servido como lugares de tránsito hacia la casa del director. Esto permitía darle una continuidad y un flujo a la interacción en ambos espacios. Instalaciones más amplias, salones para cada grupo con iluminación bilateral, buena ventilación, patios grandes y servicios accesibles hacen de estas escuelas un espacio más ordenado. ${ }^{47}$

Singulares por tener una distribución que tendía a emancipar la escuela de la casa y permitir una especialización de funciones, estos planteles coinciden con su reconocimiento en el vecindario. En parte, por la trayectoria de sus directores y por ser inmuebles muy grandes -ubicados generalmente en los nuevos fraccionamientos de la ciudad-, cuya superficie construida era de más de 500 metros cua-

\footnotetext{
${ }^{46}$ Orvañanos, "Discurso", 1895, p. 7.

${ }^{47}$ Ejemplos de establecimientos de este tipo eran las escuelas: $65,66,72,59,77,29,75$.
}

drados sin contar los patios. ${ }^{48}$ No es casual que la visibilidad de estos establecimientos se hiciera evidente no sólo por las dimensiones del edificio, sino, en su interior, por contar con un mobiliario más moderno: escritorio con sillón giratorio para el director, bancas binarias americanas nuevas, un lugar asignado para el museo escolar en cada salón, esferas terrestres, mapas en buen uso y un armonio para la clase de música. ${ }^{49}$

Los planteles diferenciados fueron ordenados con base en una jerarquización de funciones $y$, por lo general, contaron con un lugar preferente asignado a la dirección escolar. Si bien las aulas tenían un área similar a la de las escuelas extensivas (30 metros cuadrados), los reportes no indican una aglomeración en ellas. Por la distribución de los alumnos en los grados se puede observar una mayor homogeneidad en las edades y una asiduidad en la asistencia, lo que me lleva a pensar que probablemente estas escuelas se amoldaban a las aspiraciones de los padres con empleos más estables.

El área de servicios fue insuficiente como en el resto de los establecimientos de la ciudad, pues por lo regular existían tres baños para ser usados por 500 niños en promedio. Sin embargo, muchas de estas escuelas contaron con un cuarto con regaderas, lo que indica que el cuidado

${ }^{48}$ Directores como Joaquín Hernández, de la escuela elemental 77, Amelia Toro Bizcan, de la escuela elemental 126, y Miguel Oscoy, de la escuela elemental 43, eran profesores desde que los planteles pertenecían al municipio, en AHDF, Instrucción pública en general, vol. 2510.

${ }^{49}$ Los inventarios en estas escuelas estaban valuados en 3000 pesos en promedio, en AHDF, Instrucción pública, inventarios, vol. 2676. 
en el aseo de los niños tenía una mayor relación con lo que los higienistas aconsejaban.

Un ejemplo de este tipo es la escuela número 65 para niños que tenía una entrada a manera de vestíbulo, estableciendo con ello una distancia con el movimiento de la calle. Cuatro aulas dispuestas alrededor de un primer patio ofrecían una gran amplitud y buena iluminación (bilateral). Ellas conformaban el espacio escolar que además tenía un cuarto de útiles (antes cocina), un baño con regaderas y la dirección escolar. Esta última estaba ubicada de tal forma que el director podía tener una visión "panóptica" de todos los salones de clase y a la vez el control de la entrada al inmueble. Un estrecho pasillo comunicaba este espacio de la escuela con un segundo patio de mayor tamaño, con una fuente en el medio y circundado con cuatro árboles que permitían ocultar las habitaciones del director, ofrecien do cierta privacidad y un control de la interacción que se llevaba a cabo en el inmueble (véase plano 5).

La escuela número 29 ofrece otro esquema en el cual puede apreciarse cómo el director ubicó los salones de clase al establecer una correspondencia directa con sus espacios de vida, y diferenció ambos lugares a través de un patio central. Esta disposición podría obedecer a una valoración respecto a las relaciones y la dinámica que se establecían en el interior de ambos ambientes: la sala ubicada enfrente del cuarto año, como lugares en los cuales la interacción que se establecía podía ser observada desde el exterior y cuyas relaciones registraban rasgos de formalidad y autoridad; las recámaras frente a las aulas de segundo y tercer año, como espacios donde las relaciones son más cercanas; y el salón de primer año ubicado a manera de "espejo" con el comedor, expresando un lugar festivo, con mayor movilidad e incluso más disperso y ruidoso. Al fondo, frente a la cocina, fue colocado un salón para gimnasia, y un poco más allá, un cuarto para depósito de útiles escolares que tenía el cuarto de criados en correspondencia (véase plano 6).

Es en estos planteles donde el orden y la disciplina tenían su expresión, tal como se aprecia en un comunicado de una directora a sus maestras:

I. A la entrada y salida de las alumnas, exíjaseles lleven las manos atrás y el cuerpo recto marcando el paso.

II. El primer año del grupo A debe determinar su salida por las niñas de mayor estatura, marchando todas de frente y se les dará enseguida la voz de media vuelta.

III. Se recomienda especialmente al segundo año grupo $\mathrm{B}$ arregle a sus alumnas a manera que ya en el patio no estén buscando compañera y queda enteramente prohibida la costumbre de tomar a las alumnas por la mano o de la espalda a fin de colocarlas en su lugar.

IV. Al primer toque las alumnas se dispondrán a salir; al segundo [toque, saldrán] de las puertas de sus clases al patio (con paso de marcha) y al tercer [toque] que se dará desde hoy, recibirán orden para retirarse de la escuela.

v. El grupo que en patio no estuviese correctamente y en silencio, será detenido por una hora. ${ }^{50}$

La distinción de espacios -entre los del director y los de la escuela- y de tiempos -entre el escolar y el doméstico de los que

${ }^{50}$ AFIDF, Instrucción pública, vol. 2532, exps. 1-6. 


\section{SECUENCIA}

Plano 5. Escuela diferenciada

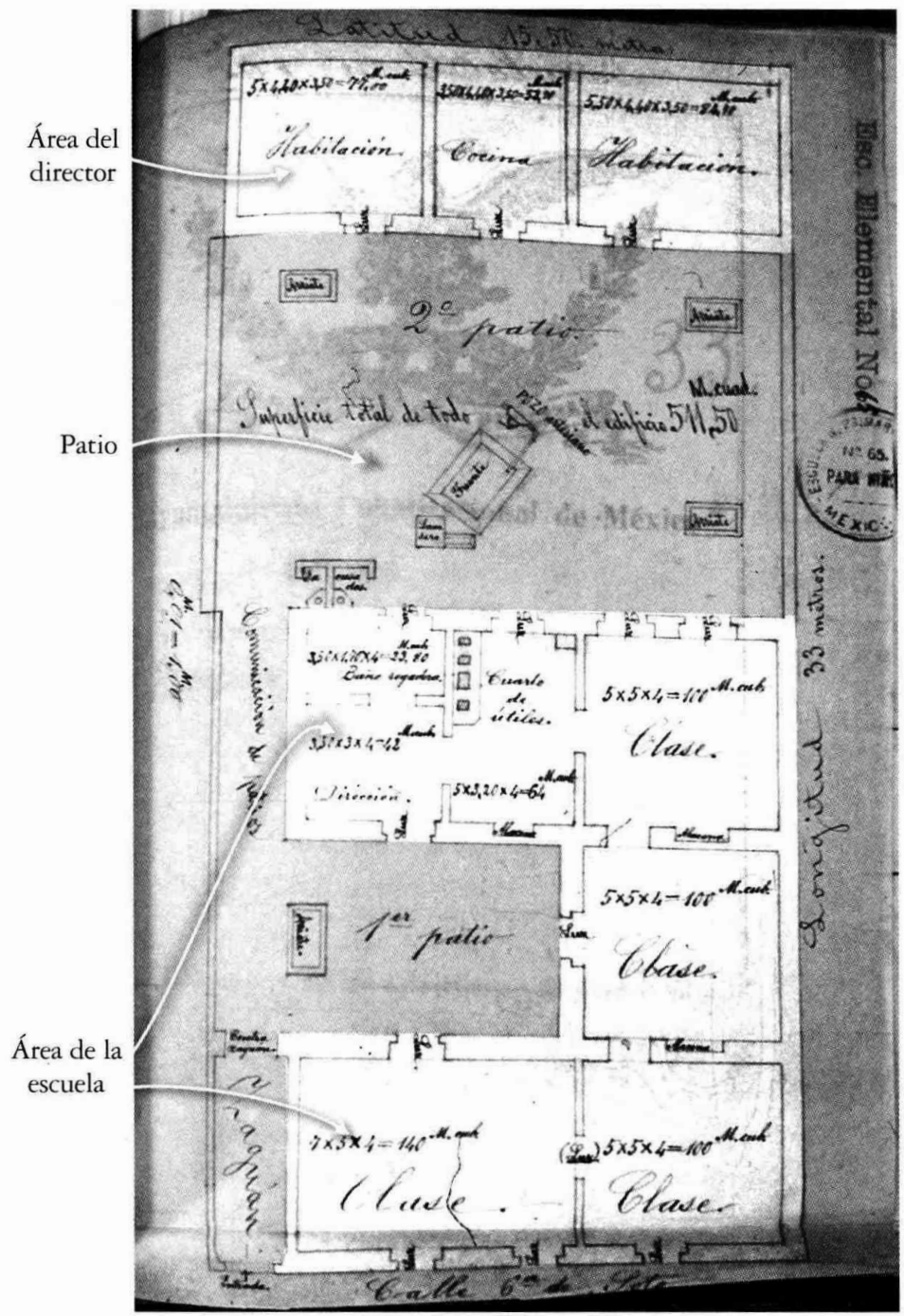

Fuente: Archivo Histórico del Distrito Federal, Instrucción pública, planos, vol. 2562. 


\section{SECUENCIA}

Plano 6. Escuela diferenciada

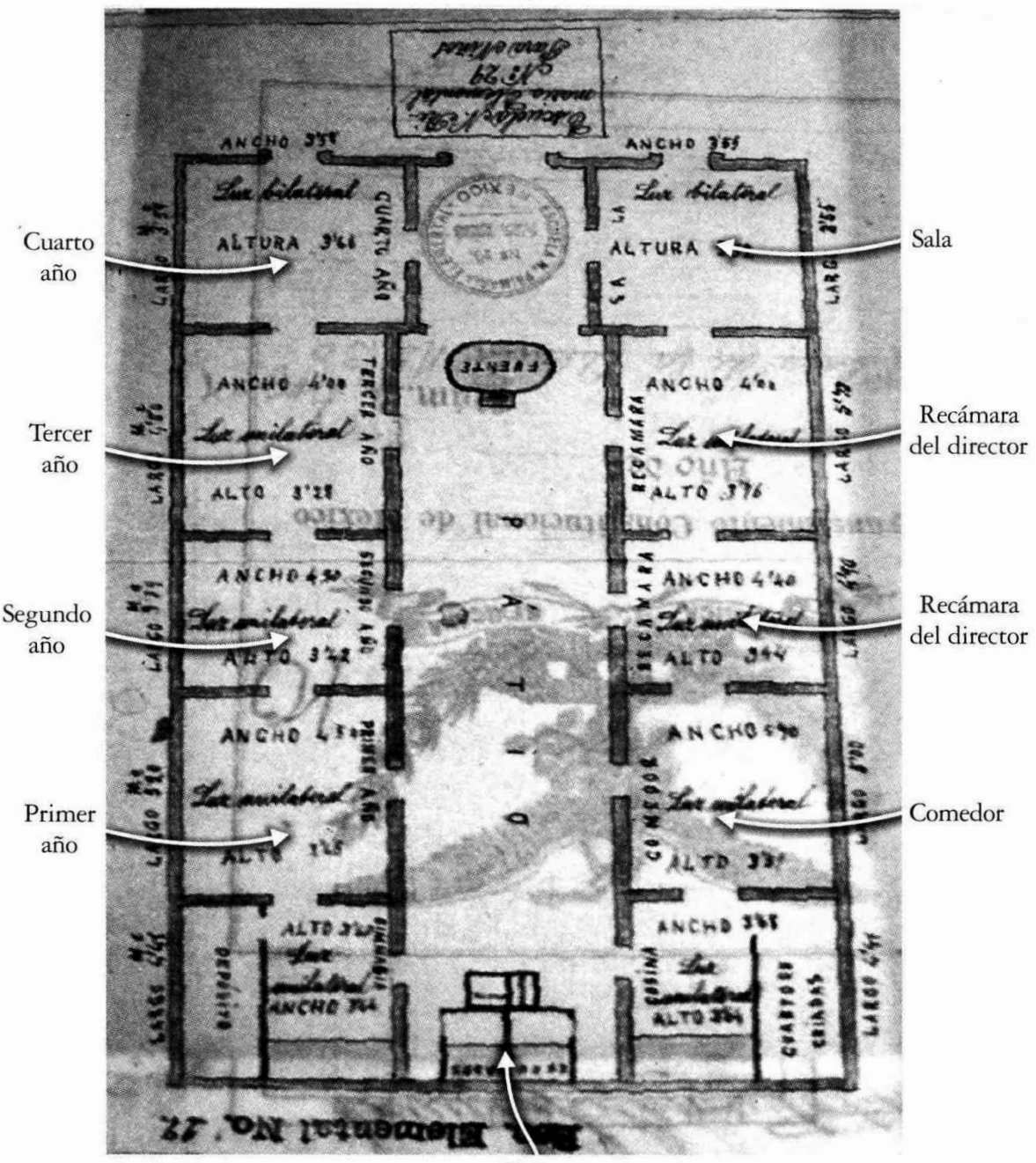

Baños

Fuente: Archivo Histórico del Distrito Federal, Instrucción pública, planos, vol. 2562. 
ahí habitaban- hacía que en estos planteles se llevara a cabo una mayor diferenciación en las funciones de los maestros y de los niños. Relaciones basadas en la distancia (no en la proximidad, ni en aglomeración) permitían que los profesores ejercieran un mayor control.

Más allá de las disposiciones de la autoridad y desde la propia iniciativa de los maestros, se practicó una ordenación basada en clasificar a los alumnos, según criterios de aprovechamiento, estatura y aseo. En estas escuelas se advierte el interés de los profesores por formar hábitos, pues los niños obtenían un lugar en función de sus logros, según los estándares establecidos (mejor conducta, mejor aplicación, mejor presentación) y se buscaba homologar el comportamiento en función de la disciplina (marchar al toque, mantener el cuerpo erguido). Es aquí donde la autoridad podía mostrar, a manera de escaparate, la implementación de los programas pedagógicos y donde los maestros podían hacer visibles sus meticulosas propuestas.

\section{CONSIDERACIONES FINALES}

No ha sido la intención de este trabajo presentar tipos de escuelas, sino un espectro que diera cuenta de la amplia gama y la heterogeneidad de condiciones de los establecimientos escolares elementales en la ciudad de México durante los últimos años del porfiriato.

A través de ellos, se puede ver que más allá de los intentos uniformadores de la enseñaza del gobierno federal, la diversidad fue algo consustancial a la oferta educativa pública. Diversidad que puede ser referida no sólo a la variedad de espacios que se adhirieron al esquema habita- cional de la ciudad, sino a la interacción que se gestó en el interior de los diferentes lugares. En efecto, los planteles educativos no guardaron un patrón en cuanto a su distribución, sino que asumieron las características de la calle, del cuartel o del barrio en el cual se asentaron. La escuela como espacio adquirió las dimensiones y la distribución que ofrecía el local donde se situó.

Pero además, el ritmo de los habitantes de la capital también se impuso y, ante ello, la autoridad tomó provisiones para que los alumnos pudieran inscribirse en cualquier época del ciclo escolar y entrar a cualquier hora. Por lo tanto, la escuela elemental urbana tuvo un flujo y movimiento constante e incorporó los rasgos de una población itinerante.

Propongo, siguiendo a algunos teóricos sociales, que la falta de un patrón de asistencia en el que los niños fueran a la misma escuela todos los días, que siguieran un horario de entrada y que mantuvieran las mismas rutas espacio-temporales en la ciudad para su acceso dificultó la integración del sistema escolar y la propia integración social hacia el sistema educativo. Según cifras oficiales, sólo $65 \%$ de los alumnos asistían regularmente a la escuela frente al total de inscritos, y si a esto aunamos la incertidumbre que significaba la movilidad en la ubicación de los mismos planteles, se puede suponer que para un amplio sector de la población acudir a la escuela no formaba parte de su rutina diaria. ${ }^{51}$

${ }^{51}$ Lezama explica los planteamientos principales de Giddens: "La integración social que es la fuente más importante de producción de relaciones sociales, se logra por los patrones de conducta que provienen de la rutinización de la actividad social. Nuestras vi- 
Por ello, sin lugar a dudas, el interés prioritario del ejecutivo fue hacer efectivo el principio de obligatoriedad, el cual prevenía que los padres remisos que no mandaran a sus hijos a la escuela se hacían acreedores de una multa de uno a cinco pesos, o el arresto correspondiente a razón de un día por cada peso de multa. ${ }^{52}$ En ese sentido, la escuela tenía que ser un espacio abierto y disponible, pero también había que insistir que los niños asistieran a los planteles en la misma demarcación donde vivían. Empadronamientos domiciliarios y control continuo de los padres, a través de consejos de vigilancia articulados en los diversos cuarteles, hacen pensar que la escuela significó un puente para que el alcance de la autoridad llegara hasta la casa e inducir, de manera coactiva, la integración hacia el sistema educativo.

No obstante, el control tenía un límite y éste era el interior del espacio escolar. El ambiente de la escuela fue una extensión de la vida familiar y doméstica de los directores. Ellos fueron dueños del lugar y le imprimieron a éste las condiciones de su vida personal. Algunos se reservaron las mejores habitaciones para uso privado, otros ocuparon un espacio menos

das se desenvuelven cotidianamente por medio de rutas familiares espacio-temporales que se intersectan con las rutas de otros actores, de tal suerte que determinados aspectos o 'regiones' de nuestra vida social constituyen patrones recurrentes de relaciones sociales." Lezama, Teoría, 1993, p. 126. Las cifras fueron obtenidas sobre el total de inscripción y la asistencia media publicados en Boletín Mensual de Estadistica Escolar, junio de 1907, en AGN, Instrucción pública, Directorio de escuelas, vol. 300 , exp. 31.

${ }^{52}$ Ley de Instrucción Obligatoria, 21 de marzo de 1891, art. 14, en Dublán y Lozano, Colección, 1908, t. 10. central. Su posición les permitió vivir en casas que no hubieran podido sufragar por su nivel de ingreso y duplicaron los beneficios económicos que eran merecedores, pues dispusieron de un sueldo íntegro al no tener que pagar renta.

Por la distribución que los directores hicieron de los alumnos en grados escolares se desprende que, en muchas ocasiones, reservaron los salones más pequeños y con peor iluminación para los alumnos de tercer y cuarto años que, por lo general, eran grupos más reducidos. También existió la tendencia a separar estudiantes de un mismo grado en aulas con condiciones muy diferentes unas de otras y a uniformar el alumnado con base en criterios personales, como se desprende de esta circular enviada en 1910:

Se ha tenido noticia en esta Secretaria que algunos directores de escuelas primarias, con el objeto quizá de tener una clientela distinguida, o bien para conseguir que sus educandos tengan un aspecto uniforme y sujeto a determinado criterio convencional, recurren a punibles procedimientos, ya sea rehusando inscribir a alumnos pobremente vestidos o exigiendo que éstos no lleven sombrero de palma, sino de pelo o teniendo pretensiones de la misma índole. Se sabe que algunas directoras imponen a las alumnas la obligación de usar vestido de cierto color, listones de anchura determinada y también de un color fijo y de clase especial bien definida, y que penan con diversos castigos a las que sus padres hacen usar prendas o adornos distintos y llegan hasta el absurdo de ordenar que reduzcan las calificaciones que por su aplicación se han hecho acreedoras las alumnas que en ese caso se encuentran. Considera esta Secretaría que solamente puede exigirse a los alumnos $y$ a las alum- 
nas de las escuelas el aseo de su persona y su vestido; juzga las prácticas que antes ha hecho referencia en completa oposición con el espíritu democrático de nuestras instituciones; $y$, en vista de que las escuelas nacionales están abiertas, no para algunos sino para todos los niños, recomienda a usted se sirva mandar poner el remedio consiguiente, y recordar a los directores que no deben emplear medida correctiva de ningún género para cambiar la indumentaria de los educandos, sino exigirles nada más el aseo y hacer uso de simple persuasión discreta y prudente, para procurar que se mejoren, en términos modestos, las condiciones en que se encuentran. ${ }^{53}$

En algunos casos, en vísperas de alguna fiesta religiosa, los directores advertían a los alumnos, de manera encubierta, que podían dejar de asistir. Y cuando se celebraba el día de su cumpleaños suspendían clases y se adornaba toda la escuela. Muchos de ellos exigían a los estudiantes la compra de útiles contrariando con ello la condición de gratuidad que debía tener la enseñanza. ${ }^{54}$ En ocasiones, a decir de la prensa, si había cuartos disponibles en los edificios, eran puestos en alquiler para completar sus ingresos. ${ }^{55}$

Así también, el que la casa del director estuviera en la escuela imprimió una estratificación rígida con pocas probabilidades de ascenso y autonomía para los demás profesores que laboraban en el plantel. Sin embargo, este entrecruza-

${ }^{53}$ AHDF, Escuela elemental 89, vol. 2555 (circular fechada el 24 de agosto de 1910).

${ }^{54}$ Circulares que aparecen en AHDF, Escuela elemental 126, vol. 2558; Escuela elemental 47, vol. 2546, y Escuela elemental 89, vol. 2555.

${ }^{55}$ Citado por Meneses, Tendencias, 1986, p. 459. miento entre hogar y escuela, entre lazos de parentesco y laborales, también significó un costo: los directores comprometieron la libertad de su persona y su vida íntima, puesta de manifiesto a cada paso por la mirada de los actores involucrados.

Ahora bien, si la escuela se fundía con la ciudad, adquiría sus ritmos y seguía sus patrones, si presentaba en su interior las peculiaridades de los que ahí habitaban, ¿cómo se hacía visible como lugar?, ¿cómo adquiría una definición específica? Si la significación del lugar se establece por el tipo de actividad que la comunidad reconoce como característica, esta diferenciación se presentó, en gran medida, fuera del ámbito espacial de la escuela.

La entrega de premios celebrada en actos que tenían una amplia notoriedad pública propició tanto el encuentro de maestros, alumnos y autoridades, como la demostración, para los habitantes de la ciudad, de lo que se podía aprender en la escuela. Se premiaba a los alumnos que se distinguían por su aplicación y a las escuelas que cumplían con el programa de estudios al final del ciclo escolar.

En las calles, la cultura escolar se mostró a la comunidad por otros medios, como las excursiones al ferrocarril o a las exposiciones, la procesión cívica en honor del presidente de la república, las visitas a museos, los ejercicios militares de los que ya se ha hablado, y las funciones de circo gratuitas para los alumnos distinguidos.

Las fiestas del Centenario fueron también ocasión para darle visibilidad a los edificios y hacer evidente su significación como espacio escolar. Se colocaron banderas y escudos a la entrada de las casas que ocupaban los planteles y se iluminaron con faroles durante todo el mes de septiembre hasta que se consumiera la 
carga diaria. La simbolización de la escuela se buscó a través de un lenguaje cívico y nacional que se promovió mediante la celebración de las fiestas patrióticas, el canto del Himno Nacional al inicio de las clases y la colocación del retrato del presidente de la república junto al de don $\mathrm{Mi}$ guel Hidalgo a la vista de los alumnos. ${ }^{56}$

La autoridad guió su actuación en el sentido de establecer un sistema escolar uniforme y buscar la integración social hacia la escuela. Ello implicó, como hemos visto, el manejo de un complejo aparato administrativo basado principalmente en el control, la vigilancia y la coacción. Sin embargo, en este proceso la disposición espacial desempeñó un papel importante. Dadas las características de los establecimientos escolares urbanos adheridos a las condiciones de las casas-habitación, la movilidad de los mismos, así como las condiciones de pobreza y falta de disposición habitacional que inducían a que buena parte de la población fuera itinerante, dificultaron la significación de la escuela elemental como lugar, que la comunidad la valorizara como un referente cultural, y que la autoridad lograra hacer de ella un ambiente cerrado con un poder disciplinario delimitado espacial y temporalmente como era su propósito.

Para 1908, la Secretaría de Instrucción Pública y Bellas Artes consideró que para que los niños se educaran y asistieran a las escuelas elementales era necesario brindarles "alimento, y que cuando también se juzgue necesario darles vestido ly calzado] para cubrir su desnudez"; y, para ello, promovió una partida presupuestal de 15000 pesos. El presupuesto sólo bas-

56 También encontramos esta información en AHDF, Escuela elemental 89, vol. 2555. tó para que dos años después se repartiera ropa a los niños más necesitados en ocasión de las fiestas del Centenario, sin embargo, en ese mismo año, la Secretaría construyó dos planteles de gran extensión para 400 y 500 alumnos en la colonia de La Bolsa.

Cada uno de ellos contó con un espacio central destinado a comedores escolares y "bancas adecuadas a la talla de los niños para estar cómodamente sentados para recibir sus alimentos". No obstante, como el dotar de alimentación no podía contravenir la educación moral de los niños y que se pensara que el Estado estaba obligado a hacerlo de manera gratuita, la comida se vendería a precios ínfimos:

si la sociedad quiere hacer de los pobres parias (que lo son hoy muchos niños mexicanos) hombres útiles, los ayude, no dándoles de una manera absolutamente gratuita los alimentos y el vestido, sino proporcionándoseles en condiciones tales de baratura, que en cierto modo equivalga a que se les dieran. ${ }^{57}$

De alguna manera y a pesar de la modalidad de esta medida, incorporar las necesidades sociales al espacio escolar fue una forma de dar respuesta a un lenguaje que la comunidad había venido esgrimiendo por medio de sus prácticas, como la asistencia fluctuante o la deserción escolar, mismas que demostraban que el hambre no era compatible con la rutina educativa.

En suma, el proceso de construir de la escuela como lugar, singularizarla, darle significado frente a otras actividades sociales fue un movimiento de doble vía, en

${ }^{57}$ Estudio acerca de los comedores escolares incluidos en AGN, "Anales", 1910, caja 285, exp. 18. 
el cual, por un lado, la disciplina administrativa buscó aplicar criterios de conducta regularizados en la comunidad y, por otro, ésta construyó sus propios referentes, intentó asimilarla y trató, a su manera, de ajustarse en el espacio y el tiempo institucionales.

\section{ARCHIVOS}

AGN Archivo General de la Nación.

AHDF Archivo Histórico del Distrito Federal.

\section{BiBLIOGRAFÍA}

- Alcántara García, Pedro, Tratado de bigiene escolar, Librería de Hernando, Madrid, 1886.

-Amerlinck, Mari-Jose y Fernando Bontempo, El entorno construido y la antropologia: introducción a su estudio interdisciplinario, CIESAS, México, 1994.

-Arnaut, Alberto, La federalización educativa en México. Historia del debate sobre la centralización y la descentralización educativa (1889-1994), COLMEX/CIDE, México, 1998.

-Bazant, Mílada, Historia de la educación durante el porfiriato, Colmex, México, 1995.

-Boletín de Instrucción Pública, Órgano de la Secretaría del Ramo, Tipografía Económica, México.

-Campo, Ángel de, Cuentos y crónicas. Micrós, SEP, México, 1944.

-Castellanos, Abraham, Organización escolar. (Ensayo crítico), Imprenta de Lorenzo San Germán, Oaxaca, 1897.

-Certeau, Michel de, La invención de lo cotidiano. 1 Artes de Hacer, Universidad Iberoamericana/Instituto Tecnológico y de Estudios Superiores de Occidente, México, 1999.

-Chaoul, Ma. Eugenia, "La instrucción municipal un espejo de la ciudad. La gestión educa- tiva del Ayuntamiento de México (1867-1896)", Anuario de Espacios Urbanos. Historia, Cultura, Diseño, UAM, 1999, México, pp. 179-214.

-Díaz Zermeño, Héctor, "La escuela nacional primaria en la ciudad de México, 1876 1910", Historia Mexicana, núm. 29, julio-septiembre de 1979.

-Dublán, Manuel y José María Lozano, Colección legislativa completa de la república mexicana, con todas las disposiciones expedidas para la federación, el Distrito y los territorios federales, Tipografía de la Viuda de Francisco Díaz de León, México 1908 , t. 10.

-Giddens, Anthony, La constitución de la sociedad. Bases para la teoria de la estructuración, Amorrortu Editores, Buenos Aires, 1998.

-Lezama, José Luis, Teoría social. Espacio y ciudad, Colmex, México, 1993.

-López Loreto, Rosalva (coord.), Casas, viviendas y hogares en la historia de México, Colmi:X, México, 2001.

-Loyo, Engracia, Gobiernos revolucionarios y educación popular en México, 1911-1928, Colmix, México, 1999.

-Martínez Jiménez, Alejandro, Origen y desarrollo de la educación primaria en México, 18701965, UAM-Xochimilco, México, 1981.

-Memorias del Primer Congreso Higiénico-Pedagógico reunido en la ciudad de México el año de 1882, Imprenta del Gobierno en Palacio, Méxi$\mathrm{co}, 1883$.

-Meneses Morales, Ernesto, Tendencias educativas oficiales en México, 1911-1934. La problemática de la educación mexicana durante la revolución y los primeros lustros de la época posrevolucionaria, Centro de Estudios Educativos, México, 1986.

-Morales, María Dolores y María Gayón, "Viviendas, casas y usos de suelo en la ciudad de México, 1848-1882" en Rosalva López (coord.), Casas, viviendas y bogares en la bistoria de México, Colmex, México, 2001.

- Orvañanos, Domingo, "Discurso pronunciado el 29 de agosto de $1895^{\circ}$ en Concurso 
Científico de la Sociedad Médica Pedro Escobedo, Oficina Tipográfica de la Secretaría de Fomento, México, 1895.

-Rapoport, Amos, Human Aspects of Urban form. Towards a Man-Environment Approaib to Urban Form and Design, Pergamon Press, Gran Bretaña, 1977.

-Rodríguez Piña, Jaime, "Las vecindades en 1811: tipología" en Seminario de Historia de México. Investigaciones sobre la ciudad de México, Departamento de Investigaciones HistóricasINAH, México, 1976, t. II.

-Ruiz, Luis E., Tratado elemental de pedagogia, Oficina Tipográfica de la Secretaría de Fomento, México, 1900.

- "Cartilla de higiene acerca de las enfermedades transmisibles destinada a la enseñanza primatia", Gaceta Médica de México, 2a. serie, 1 de junio de 1903, vol. 3, núm. 11, t. III, pp. 163-181.
-Thompson, Lanny, "Artisans, Marginals, and Proletarians: the Household of the Popular Classes in Mexico City, 1876-1950" en Virginia Guedea y Jaime E. Rodríguez (coords.), 5 Centuries of Mexican History/Cinco siglos de bistoria de México, Instituto Mora/University of California, Irvine, 1998.

-Torre V., Guadalupe de la, Sonia Lombardo de Ruiz y Jorge González Angulo, "La vivienda en la zona al suroeste de la Plaza Mayor de la ciudad de México" en Rosalva López (coord.), Casas, viviendas y hogares en la bistoria de México, Colmex, México, 2001.

-Tuan, Yi-Fu, Space and Place. The Perspective of Experience, University of Minnesota Press, Mineapolis, 1989 (la. edición 1977).

-Vaughan, Mary Kay, Estado, clases sociales y educación en México, SEP, México, 1982 (Sep-80). 